\title{
降水量变化与氮添加下荒漠草原土壤酶活性及其 影响因素
}

\author{
朱湾湾 ${ }^{1,2}$ 王 攀 2 许艺馨 2 李春环 ${ }^{2}$ 余海龙 $^{2}$ 黄菊荣 $^{1^{*}}$ \\ 1宁夏大学生态环境学院, 西北土地退化与生态恢复国家重点实验室培育基地, 西北退化生态系统恢复与重建教育部重点实验室, 银川 750021; ${ }^{2}$ 宁夏 \\ 大学地理科学与规划学院, 银川 750021
}

\begin{abstract}
摘 要 土壤酶主要由植物根系和微生物分泌产生, 参与有机质降解和元素循环等重要过程。研究降水量变化和氮(N)添加 下土壤酶活性及其与植物群落组成以及微生物活动间的联系, 可为深入理解全球变化背景下植被-土壤系统中元素的循环与 转化机制提供科学依据。该研究基于 2017 年在宁夏荒漠草原设立的降水量变化(减少 $50 \%$ 、减少 $30 \%$ 、对照、增加 $30 \%$ 以及增 加 $50 \%)$ 和 $\mathrm{N}$ 添加 $\left(0\right.$ 和 $\left.5 \mathrm{~g} \cdot \mathrm{m}^{-2} \cdot \mathrm{a}^{-1}\right)$ 的野外试验, 研究了 2018-2019年土壤蔗糖酶、脲酶和磷酸酶活性的变化, 分析了其与植物群 落组成、微生物生态化学计量特征的关系。结果表明: 与减少降水量相比, 增加降水量对 3 种酶活性的影响较大, 但其效应与 $\mathrm{N}$ 添加以及年份存在交互作用。2018年增加降水量对3种酶活性的影响缺乏明显的规律性。2019年增加降水量不同程度地提 高了3种酶活性。N添加对3种酶活性影响较小(尤其2019年); 草木樨状黄耆(Astragalus melilotoides)生物量与嫝酶和磷酸酶活 性负相关。粘隐子草(Cleistogenes squarrosa)生物量与3种酶活性正相关。除Patrick丰富度指数外, 植物群落多样性指数普遍 与 3 种酶活性负相关; 对酶活性影响较大的因子包括土壤 $\mathrm{pH}$ 、土壤全磷 $(\mathrm{P})$ 含量和微生物生物量碳 $(\mathrm{C}): \mathrm{N}: \mathrm{P}$ 。因此, 短期内降水 量变化及 $\mathrm{N}$ 添加对荒漠草原土壤酶的影响较小(尤其在减少降水量条件下); 降水量增加及 $\mathrm{N}$ 添加通过提高植物生物量、改变植 物多样性、调节微生物生物量元素平衡以及增强土壤P有效性, 直接影响着土壤酶活性。鉴于土壤酶种类的多样化和功能的 复杂性, 今后还需结合多种酶活性的长期变化规律, 深入分析全球变化对酶活性的影响机制。

关键词 干旱半干旱区; 降水格局改变; 大气氮沉降增加; 微生物生态化学计量特征; 植物群落多样性
\end{abstract}

朱湾湾, 王攀, 许艺馨, 李春环, 余海龙, 黄菊芗. (2021). 降水量变化与氮添加下荒漠草原土壤酶活性及其影响因素. 植物生态学报, 45, 309-320. DOI: 10.17521 /cjpe. 2020.0264

\section{Soil enzyme activities and their influencing factors in a desert steppe of northwestern China under changing precipitation regimes and nitrogen addition}

\author{
ZHU Wan-Wan ${ }^{1,2}$, WANG Pan $^{2}$, XU Yi-Xin ${ }^{2}$, LI Chun-Huan ${ }^{2}$, YU Hai-Long ${ }^{2}$, and HUANG Ju-Ying ${ }^{1 *}$
}

${ }^{1}$ School of Ecology and Environmental Sciences, Ningxia University, Breeding Base for State Key Laboratory of Land Degradation and Ecological Restoration in Northwestern China, Key Laboratory for Restoration and Reconstruction of Degraded Ecosystems in Northwestern China of Ministry of Education, Yinchuan 750021, China; and ${ }^{2}$ School of Geography Science and Planning, Ningxia University, Yinchuan 750021, China

\begin{abstract}
Aims Soil enzymes, which are mainly produced by plant roots and soil microbes, involve in the organic matter degradation and element cycling and other key processes in plant-soil systems. Study on the relationships between soil enzyme activity and plant community composition and microbial activity under changing precipitation pattern and increasing nitrogen $(\mathrm{N})$ deposition can provide a new insight for evaluating the influencing mechanism of global change on the biogeochemical cycling in plant-soil systems.

Methods Based on a field experiment involving five precipitation treatments (50\% reduction, 30\% reduction, natural precipitation, $30 \%$ increase, and $50 \%$ increase) and two $\mathrm{N}$ addition treatments $\left(0\right.$ and $\left.5 \mathrm{~g} \cdot \mathrm{m}^{-2} \cdot \mathrm{a}^{-1}\right) \mathrm{con}-$ ducted in a desert steppe of Ningxia since 2017, the changes of soil enzyme activities (sucrase, urease, and phosphatase) were studied and their relationships with plant community composition and microbial ecological stoichiometry were analyzed in 2018 and 2019.

收稿日期Received: 2020-08-03 接受日期Accepted: 2020-12-22

基金项目：宁夏高等学校一流学科建设(生态学)项目(NXYLXK2017B06)和国家自然科学基金(31760144和41961001)。Supported by the Project of First-Class Discipline Construction (Ecology) for Ningxia Higher Education (NXYLXK2017B06), and the National Natural Science Foundation of China (31760144 and 41961001).

* 通信作者Corresponding author (juyinghuang@163.com)
\end{abstract}


Important findings Compared with decreasing precipitation, increasing precipitation had greater impacts on the three enzyme activities, but its effects were interacted with $\mathrm{N}$ addition and sampling year. Increasing precipitation had no significant impacts on the three enzyme activities in 2018, but enhanced them in 2019. By contrast, N addition had less influences on the three enzyme activities, especially in 2019. The biomass of Astragalus melilotoides was negatively correlated with urease and phosphatase activities, while the biomass of Cleistogenes squarrosa had positive correlation with the three enzyme activities. Except the Patrick richness index, plant community diversity indices were generally negatively correlated with the three enzyme activities. Soil enzyme activities were more greatly affected by soil $\mathrm{pH}$, soil total phosphorus (P), and microbial biomass carbon (C):N:P. Therefore, short-term precipitation change and $\mathrm{N}$ addition have little effects on the soil enzymes in the studied desert steppe (especially under reducing precipitation); increasing precipitation and $\mathrm{N}$ addition could pose direct influences on soil enzyme activities by increasing plant biomass, changing plant diversity, regulating microbial biomass ecological stoichiometry, and enhancing soil P availability. Given the diversity and functional complexity of soil enzymes, it is necessary to deeply analyze the influencing mechanism of global change on enzyme activities by measuring the long-term responses of various enzyme activities.

Key words arid and semi-arid region; changing precipitation regimes; increasing atmospheric nitrogen deposition; microbial ecological stoichiometry; plant community diversity

Zhu WW, Wang P, Xu YX, Li CH, Yu HL, Huang JY (2021). Soil enzyme activities and their influencing factors in a desert steppe of northwestern China under changing precipitation regimes and nitrogen addition. Chinese Journal of Plant Ecology, 45, 309-320. DOI: $10.17521 /$ cjpe. 2020.0264

降水格局改变和大气氮 $(\mathrm{N})$ 沉降增加是全球变 化的两个重要表现(IPCC, 2013)。全球变暖背景下, 降水量在全球范围内呈增加趋势，同时表现出时空 分配不均和极端事件频发等特征(IPCC, 2013)。据报 道, 我国西北地区的西部生态区降水量呈增加趋势, 东部生态区降水量有所降低(高继卿等, 2015)。此外, 人类活动导致全球大气 $\mathrm{N}$ 沉降速率持续增加 (Kanakidou et al., 2016)。就中国而言, 虽然 $\mathrm{N}$ 沉降速 率在一些南方省市有所下降, 但在西北部分区域呈 增加趋势(Yu et al., 2017, 2019)。西北干旱半干旱区 生态系统稳定性差, 对环境变化敏感, 是我国典型 的生态脆弱区之一。作为该区的主要限制因子, 降 水和 $\mathrm{N}$ 调控着土壤资源有效性, 影响着植物生长和 微生物活动等关键生态过程, 与植被-土壤系统的 稳定性密切相关。目前, 国内已有较多研究探讨了 降水和 $\mathrm{N}$ 添加对该脆弱生态区的影响, 尚缺乏二者 交互作用的相关报道。鉴于降水在介导 $\mathrm{N}$ 沉降效应 中发挥着重要作用(Lü et al., 2012), 因此有必要针 对西北干旱半干旱区典型生态系统开展二者交互效 应的研究。

土壤酶主要由植物根系和微生物分泌产生, 是 土壤中元素生物地球化学循环的催化剂(马文文等, 2014)。一方面, 土壤酶活性能够反映土壤元素(碳 (C)、 $\mathrm{N}$ 、磷 $(\mathrm{P})$ 等)转化和物质循环的速率(Burns et al., 2013), 并通过对土壤养分状况的影响改变植物养
分策略。同时，土壤酶能够实现植物营养元素和有 机质的循环转化, 对土壤微环境的元素平衡和转化 具有重要影响(张美曼等, 2020)。另一方面, 土壤酶 活性可表征微生物的养分需求、反映微生物在环境 波动时维持养分平衡的应对策略(闰钟清等, 2017a)。土壤酶活性主要受土壤养分可利用性(李艳 红等, 2020)、植被类型(李静等, 2013)和微生物活性 (阊钟清等, 2017a)等因素的影响。降水和N添加通过 调控土壤水分和养分有效性, 改变植物资源利用策 略, 从而直接影响到植被结构(张金风和许雨晴, 2016)和微生物活性(王杰等, 2014a), 进而改变土壤 酶活性(许华等, 2018)。因此, 揭示降水量变化和 N 添加下土壤酶活性与植物和微生物的联系, 可为评 价全球变化背景下植被-土壤系统功能提供新思路。

荒漠草原是我国西北干旱半干旱区主要的草原 生态系统类型，其植被结构简单、生态系统脆弱。 宁夏荒漠草原主要分布于毛乌素沙地西南缘, 是区 域重要的生态屏障。该生态系统降水量少、蒸发量 大、 $\mathrm{N}$ 沉降临界负荷低, 降水和 $\mathrm{N}$ 是其植被生长和微 生物活动的主要限制因子, 因此对降水格局改变和 $\mathrm{N}$ 沉降增加较为敏感(段雷等, 2002; 杨蓉和赵多平, 2018)。那么, 降水量和N添加及其交互作用如何影 响荒漠草原土壤酶活性, 降水量改变和 $\mathrm{N}$ 添加下土 壤酶活性与植物群落组成以及微生物活动存在怎样 的联系等问题, 都值得我们进行深入探讨。为此, 本 
项目组于 2017 年在宁夏荒漠草原设立了降水量改变 及N添加的裂区试验，研究了2018-2019年生长季旺 盛期土壤酶活性的变化特点, 分析了其与植物群落 组成以及微生物生物量 $\mathrm{C}: \mathrm{N}: \mathrm{P}$ 生态化学计量特征(其 值高低与微生物活动的方向密切相关)的关系, 为 充分认识降水量变化和 $\mathrm{N}$ 添加对土壤酶活性的影响 机制提供基础数据, 并为深入理解全球变化背景下 西北脆弱生态区的元素生物地球化学循环提供理论 依据。

\section{1 材料和方法}

\section{1 研究区概况}

试验样地设立于宁夏盐池县柳杨堡乡杨寨子村 围栏草地内 $\left(37.80^{\circ} \mathrm{N}, 107.45^{\circ} \mathrm{E}\right)$, 海拔约为 1367 $\mathrm{m}$ 。该草地自1998年开始围封, 属于黄土高原向鄂 尔多斯台地的过渡地带, 具有典型的温带大陆性气 候: 年蒸发量为 $2131.8 \mathrm{~mm}$; 年降水量为 $289.4 \mathrm{~mm}$ 。 降水季节分配不均, 多集中在生长季的 5-9月; 年 平均气温为 $7.7{ }^{\circ} \mathrm{C}, 1$ 月和 7 月平均气温分别为 -8.9 和 $22.5{ }^{\circ} \mathrm{C}$ 。土壤类型为灰钙土, 土壤质地为沙壤土, 且土壤pH偏高, 呈碱性。研究区土壤基本理化性质 见表 1 。植物群落结构简单, 植被组成以一年生或多 年生草本为主, 优势物种包括猪毛蒿 (Artemisia scoparia)、牛枝子(Lespedeza potaninii)和草木樨状 黄耆(Astragalus melilotoides)等, 常见物种包括白草 (Pennisetum centrasiaticum)、针茅(Stipa capillata)和 糙隐子草(Cleistogenes squarrosa)等。

\section{2 试验设计}

于2017年9月, 在围栏草地内选择 $30 \mathrm{~m} \times 50 \mathrm{~m}$ 的区域作为降水量和 N添加处理的试验样地。降水 增减量依据近几十年来我国西北地区的西部生态区
降水量增加而东部生态区降水量减少的趋势进行设 置, 同时参考了国内同类研究方法(Xu et al., 2018)。 氮肥施用量依据区域N沉降水平(顾峰雪等, 2016)和 N饱和阈值(Tian et al., 2016)进行设置。试验设计采 用随机区组的裂区设计, 主区为降水量, 副区为 $\mathrm{N}$ 添加。降水量处理包括减少 $50 \%(\mathrm{~W} 1)$ 、减少 $30 \%$ (W2)、对照(自然降水量, W3)、增加 $30 \%$ (W4)和增 加 $50 \%(\mathrm{~W} 5)$ 。 $\mathrm{N}$ 添加处理包括 $0 \mathrm{~g} \cdot \mathrm{m}^{-2} \cdot \mathrm{a}^{-1}$ (N0)和 $5 \mathrm{~g} \cdot \mathrm{m}^{-2} \cdot \mathrm{a}^{-1}$ (N5)。试验包含 10 个处理, 每个处理 3 次 重复, 共计 30 个小区(表2)。每个主区面积为 $8 \mathrm{~m} \times$ $8 \mathrm{~m}$, 每个副区面积为 $4 \mathrm{~m} \times 8 \mathrm{~m}$ 。各主区之间设置 $1.5 \mathrm{~m}$ 的缓冲带。各主区的两个副区间垂直下埋 $1 \mathrm{~m}$ 宽的塑料布, 上埋 $20 \mathrm{~cm}$ 宽的彩钢板, 用来防止试验 干扰。

降水量减少处理采用自制的减雨架进行全年遮 雨。减雨架上端离地约 $1.8 \mathrm{~m}$, 用 $5 \mathrm{~cm}$ 宽的瓦面状高 透光性聚氯乙烯板搭建分别相当于 $50 \%$ 和 $30 \%$ 小区 面积的遮雨面。降水量增加处理采用人工喷灌装置 实现。喷水时间为每年5-8月的每月月初和月中。选 用分析纯 $\mathrm{NH}_{4} \mathrm{NO}_{3}(34 \% \mathrm{~N})$ 进行 $\mathrm{N}$ 添加处理。施 $\mathrm{N}$ 时 间为每年5-8月的每月月初。详细的试验处理方法见 朱湾湾等(2019)。

\section{3 样品采集与测定}

分别于 2018 和 2019 年 8 月下旬, 采用内径为 5 $\mathrm{cm}$ 的土钻收集每个小区 $0-20 \mathrm{~cm}$ 土壤样品。每个小 区内随机取 3 钻, 混匀后分为两部分。一部分装入铝 盒中, 采用称质量法进行含水量的测定。另一部分 过 $2 \mathrm{~mm}$ 标准篎后再分装为两部分：一部分置于冰 箱中 $4{ }^{\circ} \mathrm{C}$ 下冷藏保存, 用于蔗糖酶活性、脲酶活性、 磷酸酶活性、 $\mathrm{pH}$ 、电导率、 $\mathrm{NH}_{4}^{+}-\mathrm{N} 、 \mathrm{NO}_{3}^{-}-\mathrm{N}$ 、速效 P含量、微生物生物量的测定; 另一部分自然风干后,

表1 降水和氮(N)添加处理前试验样地 $0-20 \mathrm{~cm}$ 土壤理化性质(平均值土标准误)

Table 1 Soil physical and chemical properties in 0-20 cm layer of experimental field before precipitation and nitrogen (N) addition treatments (mean $\pm S E$ )

\begin{tabular}{|c|c|c|c|c|c|c|}
\hline $\mathrm{pH}$ & $\begin{array}{c}\text { 有机碳含量 } \\
\text { Organic carbon } \\
\text { content }\left(\mathrm{g} \cdot \mathrm{kg}^{-1}\right)\end{array}$ & $\begin{array}{c}\text { 全氮含量 } \\
\text { Total nitrogen }(\mathrm{N}) \\
\text { content }\left(\mathrm{g} \cdot \mathrm{kg}^{-1}\right)\end{array}$ & $\begin{array}{c}\text { 全磷含量 } \\
\text { Total phosphorus }(\mathrm{P}) \\
\text { content }\left(\mathrm{g} \cdot \mathrm{kg}^{-1}\right)\end{array}$ & $\begin{array}{c}\mathrm{NH}_{4}^{+}-\mathrm{N} \text { 含量 } \\
\text { Ammonium N } \\
\text { content }\left(\mathrm{mg} \cdot \mathrm{kg}^{-1}\right)\end{array}$ & $\begin{array}{c}\mathrm{NO}_{3}^{-}-\mathrm{N} \text { 含量 } \\
\text { Nitrate } \mathrm{N} \text { content } \\
\quad\left(\mathrm{mg} \cdot \mathrm{kg}^{-1}\right)\end{array}$ & $\begin{array}{c}\text { 速效磷含量 } \\
\text { Available P content } \\
\left(\mathrm{mg} \cdot \mathrm{kg}^{-1}\right)\end{array}$ \\
\hline $8.85 \pm 0.01$ & $3.70 \pm 0.11$ & $0.48 \pm 0.00$ & $0.34 \pm 0.01$ & $1.83 \pm 0.07$ & $9.96 \pm 0.59$ & $2.55 \pm 0.29$ \\
\hline
\end{tabular}

表2 试验处理及其代码

Table 2 Experimental treatments and their abbreviations

\begin{tabular}{|c|c|c|c|c|c|}
\hline $\begin{array}{l}\text { 试验处理 } \\
\text { Experimental } \\
\text { treatment }\end{array}$ & $\begin{array}{l}\text { 降水量减少 } 50 \% \\
50 \% \text { reduction in } \\
\text { precipitation }\end{array}$ & $\begin{array}{l}\text { 降水量减少 } 30 \% \\
30 \% \text { reduction in } \\
\text { precipitation }\end{array}$ & $\begin{array}{l}\text { 自然降水量 } \\
\text { Natural precipitation }\end{array}$ & $\begin{array}{l}\text { 降水量增加 } 30 \% \\
30 \% \text { increase in } \\
\text { precipitation }\end{array}$ & $\begin{array}{l}\text { 降水量增加 } 50 \% \\
50 \% \text { increase in } \\
\text { precipitation }\end{array}$ \\
\hline $0 \mathrm{~g} \mathrm{~N} \cdot \mathrm{m}^{-2} \cdot \mathrm{a}^{-1}$ & W1N0 & W2N0 & W3N0 & W4N0 & W5N0 \\
\hline $5 \mathrm{~g} \mathrm{~N} \cdot \mathrm{m}^{-2} \cdot \mathrm{a}^{-1}$ & W1N5 & W2N5 & W3N5 & W4N5 & W5N5 \\
\hline
\end{tabular}


用于有机C、全N和全P含量的测定。

各指标的测定中, 蔗糖酶活性采用 3,5 二硝基水 杨酸比色法, 腿酶活性采用苯酚钠-次氯酸钠比色 法, 磷酸酶活性采用对硝基苯磷酸盐法(刘红梅等, 2018), 有机C含量采用重铬酸钾容量法-外加热法, 全N含量采用凯氏定氮法, 全P含量采用钼锑抗比 色法, $\mathrm{pH}$ 采用酸度计法, 电导率采用便携式电导率 仪, $\mathrm{NH}_{4}^{+}-\mathrm{N}$ 和 $\mathrm{NO}_{3}^{-}-\mathrm{N}$ 含量采用连续流动分析仪(Auto Analyzer 3, SEAL Analytical GmbH, Hanau, Germany), 速效P含量采用 $0.5 \mathrm{~mol} \cdot \mathrm{L}^{-1} \mathrm{NaHCO}_{3}$ 法, 微生物生物 量 $\mathrm{C}$ 含量采用氯仿熏蒸- $\mathrm{K}_{2} \mathrm{SO}_{4}$ 浸提-碳分析仪器法, 微生物生物量 $\mathrm{N}$ 含量采用氯仿熏蒸- $\mathrm{K}_{2} \mathrm{SO}_{4}$ 提取-流动 注射氮分析仪器法, 微生物生物量 $\mathrm{P}$ 含量采用氯仿 熏蒸- $\mathrm{K}_{2} \mathrm{SO}_{4}$ 提取-Pi测定-外加Pi矫正法。

同期, 在每个小区内随机选取 $1 \mathrm{~m} \times 1 \mathrm{~m}$ 的小样 方进行植被群落调查。调查指标包括物种数和物种 高度等。调查结束后, 齐平地面剪下地上部分, 按牛 枝子、草木樨状黄耆、白草、针茅、糙隐子草及其 他物种归类分装于纸袋中带回实验室烘干 $\left(65{ }^{\circ} \mathrm{C}\right.$, $48 \mathrm{~h}$ )称质量。群落生物量为所有物种生物量之和。 植物群落多样性采用Patrick丰富度指数、ShannonWiener多样性指数、Simpson优势度指数和Pielou均 匀度指数等指标来表征, 具体计算方法见朱湾湾等 (2019)。2018年植物生物量、群落多样性以及土壤 理化性质引自朱湾湾等(2019)。2019年植物生物量、 群落多样性以及土壤理化性质的结果见附录 I-IV。

\section{4 数据分析}

采用SigmaPlot 12.0进行图的绘制。采用SPSS 19.0进行数据的统计分析: 采用 $\mathrm{K}-\mathrm{S}$ 检验进行数据 的正态分布检验; 采用三因素方差分析法分析年 份、降水量、 N添加及其交互作用对土壤酶活性的 影响; 采用单因素方差分析进行相同 $\mathrm{N}$ 添加水平下 各指标在不同降水量处理间, 以及相同降水量下各 指标在不同 $\mathrm{N}$ 处理间的差异分析。若方差为齐性, 选
用最小显著性差异(LSD)法，否则选用Games-Howell 法; 由于植物生物量能够影响土壤酶活性(杨万勤 和王开运，2002), 故采用线性回归方程拟合土壤酶 活性与植物种群生物量以及群落多样性之间的关 系。采用Canoco 5.0进行土壤酶活性与微生物生物 量 $\mathrm{C}: \mathrm{N}: \mathrm{P}$ 生态化学计量特征及其他环境因子对应关 系的午余分析(RDA)。分析前, 先对数据进行对数 转换, 以减少数据间差异。以全部环境因子作为解 释变量, 以土壤酶活性作为响应变量, 依据解释变 量前项选择, 剔除影响力较小的解释变量后进行 RDA, 并通过蒙特卡洛置换检验得出每个环境因子 的条件效应。

\section{2 结果和分析}

\section{1 降水量及N添加对土壤酶活性的影响}

年份、降水量处理、 $\mathrm{N}$ 添加以及年份与降水量 的交互作用对蔗糖酶和嫝酶活性有极显著影响(表3, $p<0.01$ )。降水量与 $\mathrm{N}$ 添加以及年份、降水量与 $\mathrm{N}$ 添 加对腿酶活性有显著的交互作用 $(p<0.05)$ 。年份、 降水量以及二者与 $\mathrm{N}$ 添加的交互作用对磷酸酶活性 有极显著影响 $(p<0.01)$ 。

2018年, 与减少降水量相比, 增加降水量对 3 种 酶活性影响较大, 且其影响程度与 $N$ 添加有关(图1): 在 $0 \mathrm{~g} \cdot \mathrm{m}^{-2} \cdot \mathrm{a}^{-1}$ 的 $\mathrm{N}$ 添加水平下, 与自然降水量相比, 仅增加 $30 \%$ 降水量显著影响了脲酶活性 $(p<0.05)$, 其他处理对 3 种酶活性无显著影响 $(p>0.05)$; 在 $5 \mathrm{~g} \cdot \mathrm{m}^{-2} \cdot \mathrm{a}^{-1}$ 的 $\mathrm{N}$ 添加水平下, 与自然降水量相比, 增 减 $30 \%$ 和 $50 \%$ 降水量对蔗糖酶活性无显著影响 $(p>$ $0.05)$, 而增减 $30 \%$ 和 $50 \%$ 降水量均显著降低了脲酶 活性，增减 $50 \%$ 降水量均显著降低了磷酸酶活性 $(p<0.05)$; 两个 $\mathrm{N}$ 添加水平间, 自然降水量以及增 加 $50 \%$ 降水量条件下 $\mathrm{N}$ 添加显著提高了蔗糖酶活性 $(p<0.05)$, 自然降水量以及增减 $50 \%$ 降水量条件下 $\mathrm{N}$ 添加显著提高了嫝酶活性 $(p<0.05)$, 减少 $50 \%$ 降

表3 年份 $(\alpha)$ 、降水量 $(\beta)$ 、氮添加 $(\gamma)$ 及其交互作用对土壤酶活性的影响

Table 3 Effects of sampling year $(\alpha)$, precipitation $(\beta)$, nitrogen addition $(\gamma)$, and their interactions on soil enzyme activities

\begin{tabular}{lcccccc}
\hline 差异来源 & $\alpha$ & $\beta$ & $\gamma$ & $\alpha \times \beta$ & $\alpha \times \gamma$ & $\alpha \times \gamma$ \\
Difference source & & & & & \\
\hline SA & $25.571^{* *}$ & $4.421^{* *}$ & $24.767^{* *}$ & $5.802^{* *}$ & 0.179 & 0.433 \\
UA & $385.536^{* *}$ & $5.662^{* *}$ & $8.980^{* *}$ & $4.755^{* *}$ & 0.563 & $3.530^{*}$ \\
PA & $186.338^{* *}$ & $7.070^{* *}$ & 3.716 & 16.133 & 1.207 & $2.959^{*}$ \\
\hline
\end{tabular}

表中数据为 $F$ 值。SA、UA和PA分别代表蔗糖酶、脲酶和磷酸酶活性。*和**分别代表显著性水平小于 0.05 和 0.01 。

Data in the table are $F$ values. SA, UA, and PA represent sucrase, urease, and phosphatase activities, respectively. * and ** indicate that the significant levels are less than 0.05 and 0.01 , respectively.

www.plant-ecology.com 

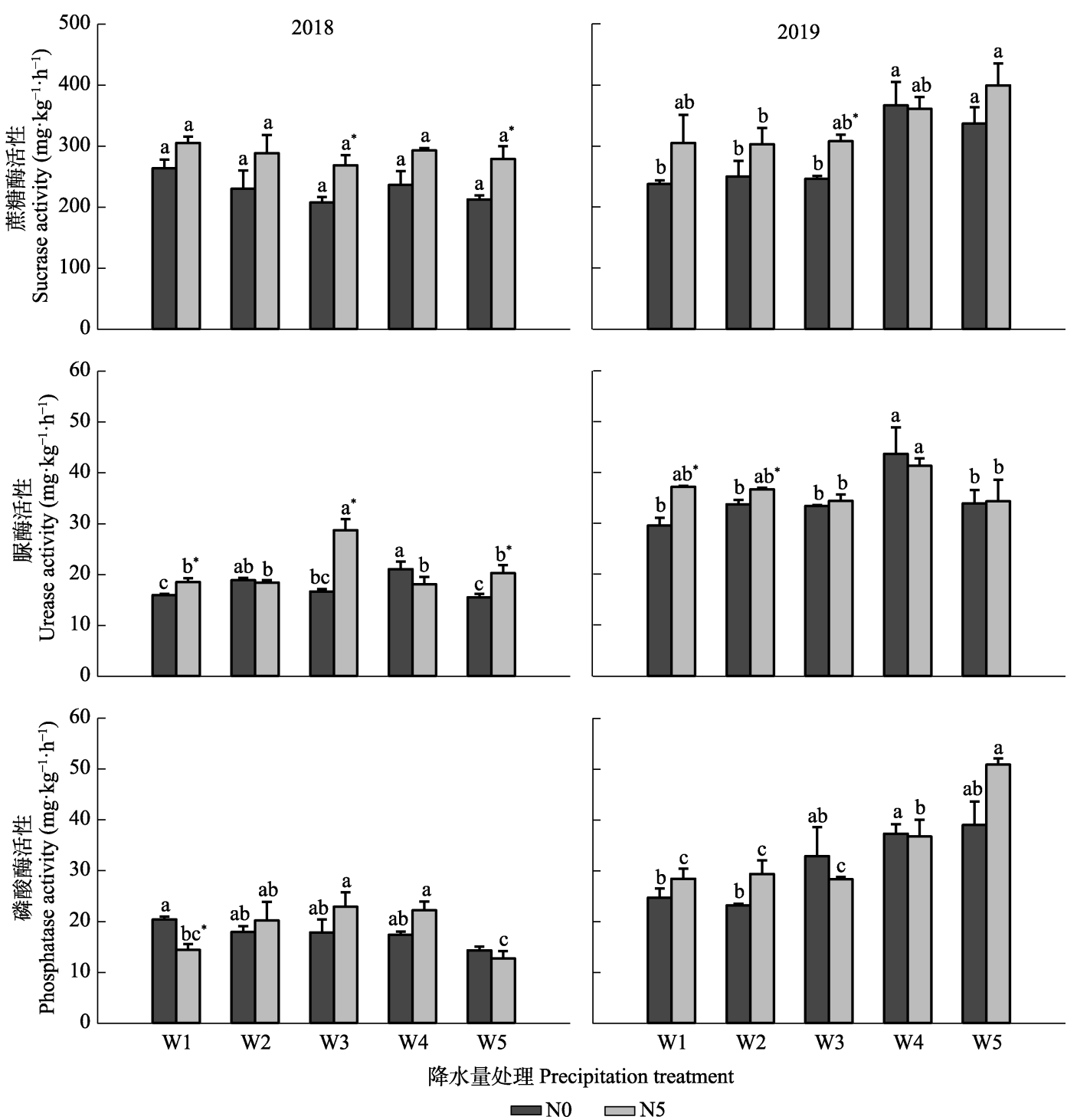

图1 2018和2019年降水量及氮(N)添加对土壤酶活性的影响(平均值土标准误)。W1、W2、W3、W4和W5分别代表降水量减 少 $50 \%$ 、减少 $30 \%$ 、自然降水、增加 $30 \%$ 和增加 $50 \%$ 。 $\mathrm{N} 0$ 和 $\mathrm{N} 5$ 分别代表 0 和 $5 \mathrm{~g} \cdot \mathrm{m}^{-2} \cdot \mathrm{a}^{-1}$ 的 $\mathrm{N}$ 添加水平。不同小写字母表示相同 $\mathrm{N}$ 添加水平下降水量处理间各指标存在显著性差异 $(p<0.05)$ 。 *表示相同降水量下 $\mathrm{N}$ 添加处理间各指标存在显著性差异 $(p<$ $0.05)$ 。

Fig. 1 Effects of precipitation and nitrogen addition on soil enzyme activities in 2018 and 2019 (mean \pm SE). W1, W2, W3, W4, and W5 represent $50 \%$ reduction in precipitation, $30 \%$ reduction in precipitation, natural precipitation (control), $30 \%$ increase in precipitation, $50 \%$ increase in precipitation, respectively. N0 and N5 represent 0 and $5 \mathrm{~g} \cdot \mathrm{m}^{-2} \cdot \mathrm{a}^{-1}$ of nitrogen addition level, respectively. Different lowercase letters indicate significant difference $(p<0.05)$ of indices among precipitation treatments under the same nitrogen addition level. * indicates significant difference $(p<0.05)$ of indices among nitrogen addition treatments under the same precipitation.

水量条件下 $N$ 添加显著降低了磷酸酶活性 $(p<0.05)$ 。

2019年, 与自然降水量相比, 减少降水量对 3 种 酶活性无显著影响 $(p>0.05)$, 增加降水量不同程度 地提高了 3 种酶活性, 但其效应在 $\mathrm{N}$ 添加处理间差异 较小(图1): 在 $0 \mathrm{~g} \cdot \mathrm{m}^{-2} \cdot \mathrm{a}^{-1}$ 的 $\mathrm{N}$ 添加水平下, 与自然降 水量相比, 增加 $30 \%$ 和 $50 \%$ 降水量均显著提高了蔗 糖酶活性 $(p<0.05)$, 增加 $30 \%$ 降水量显著提高了脲 酶活性 $(p<0.05)$; 在 $5 \mathrm{~g} \cdot \mathrm{m}^{-2} \cdot \mathrm{a}^{-1}$ 的 $\mathrm{N}$ 添加水平下, 与
自然降水量相比, 增加 $30 \%$ 降水量显著增加了脲酶 活性 $(p<0.05)$, 增加 $30 \%$ 和 $50 \%$ 降水量均显著增加 了磷酸酶活性 $(p<0.05)$; 两个 $\mathrm{N}$ 添加水平间, 自然 降水量条件下 $\mathrm{N}$ 添加显著提高了蔗糖酶活性 $(p<$ $0.05)$, 减少 $30 \%$ 和 $50 \%$ 降水量条件下 $\mathrm{N}$ 添加显著提 高了脲酶活性 $(p<0.05)$ 。

\section{2 土壤酶活性与植物群落组成的关系}

图2中，蔗糖酶活性随着白草以及粘隐子草生 

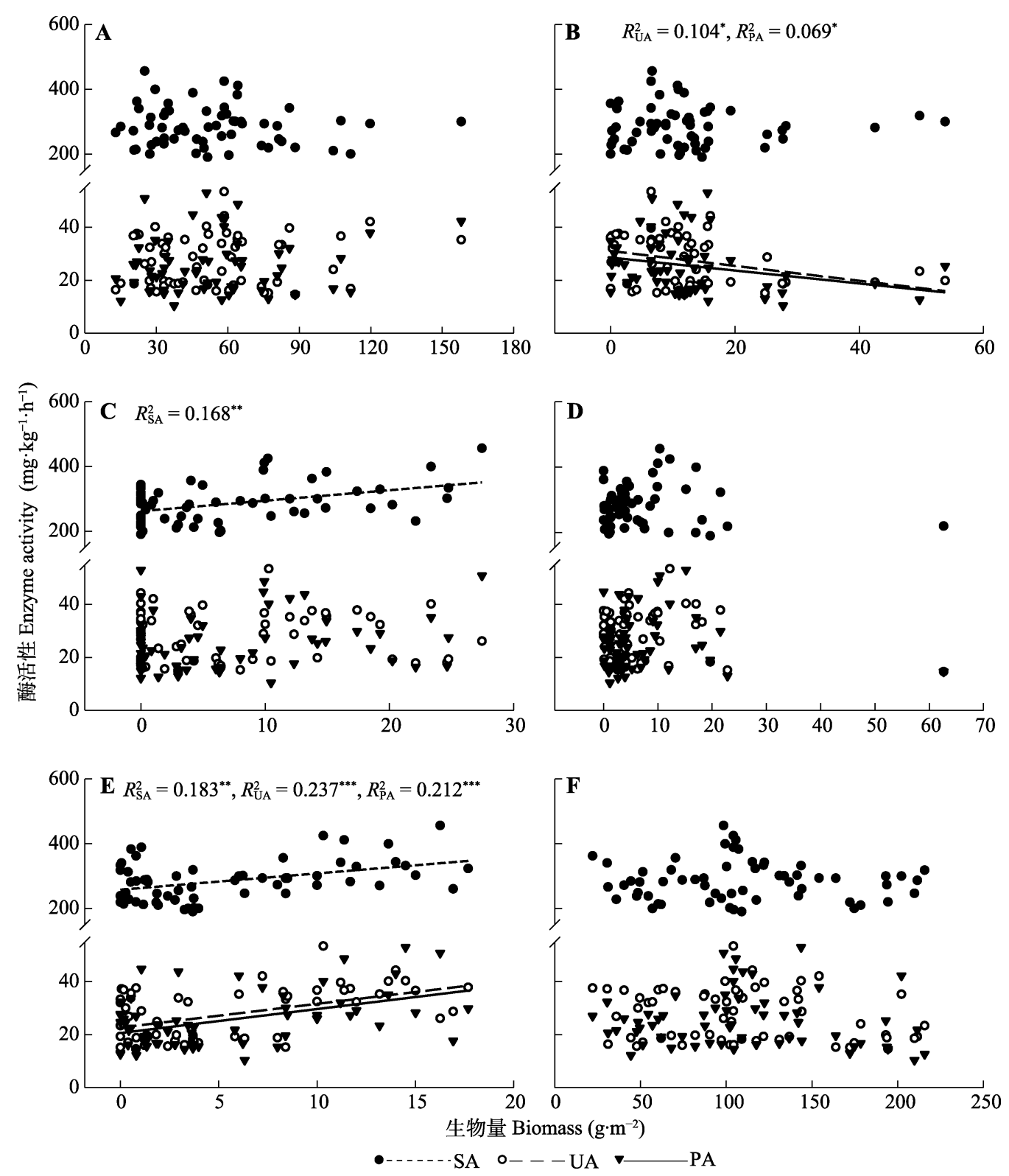

图2 土壤酶活性与植物生物量的关系。A、B、C、D和E分别表示牛枝子、草木樨状黄耆、白草、针茅和粘隐子草的种群生 物量。F代表群落生物量。SA、UA和PA分别代表庶糖酶、脲酶和磷酸酶活性。*、**和***分别表示 $p<0.05 、 p<0.01$ 和 $p<0.001$ 。 Fig. 2 Relationships between soil enzyme activities and plant biomass. A, B, C, D and $\mathbf{E}$ represent the population biomass of Lespedeza potaninii, Astragalus melilotoides, Pennisetum centrasiaticum, Stipa capillata, Cleistogenes squarrosa, respectively. F represents the community biomass. SA, UA, and PA represent sucrase, urease, and phosphatase activities, respectively. $*{ }^{* *}$ and $* * *$ indicate $p<0.05, p<0.01$ and $p<0.001$, respectively.

物量的增加而增加 $(p<0.05)$; 脲酶活性随着草木樨 状黄耆生物量的增加而减少，随着䊁隐子草生物量 的增加而增加 $(p<0.05)$; 磷酸酶活性随着草木樨状 黄耆生物量的增加而减少，随着糙隐子草生物量的 增加而增加 $(p<0.05)$ 。

如图3所示，蔗糖酶活性随着Patrick丰富度指 数的增加而增加、随着 Pielou均匀度指数以及 Simpson优势度指数的增加而减小 $(p<0.05)$; 脲酶 活性随着 Shannon-Wiener多样性指数以及Pielou均
匀度指数的增加而减小 $(p<0.05)$; 磷酸酶活性随着 Shannon-Wiener多样性指数、Pielou均匀度指数以及 Simpson优势度指数的增加而减小 $(p<0.05)$ 。

2.3 土壤酶活性与微生物生态化学计量特征及其 他环境因子的冗余分析

两个典范轴累计方差解释率为 $64 \%$ 。对土壤酶 活性影响显著的因子包括土壤 $\mathrm{pH}$ 、土壤全P含量、 微生物生物量 $\mathrm{C}: \mathrm{P}$ 、微生物生物量 $\mathrm{C}: \mathrm{N}$ 、土壤 $\mathrm{N}: \mathrm{P}$ 、 微生物生物量 $\mathrm{C}$ 、微生物生物量P含量、土壤 $\mathrm{C}: \mathrm{P}$ 、 
土壤 $\mathrm{NH}_{4}^{+}-\mathrm{N}$ 、微生物生物量 $\mathrm{N}$ 和土壤 $\mathrm{NO}_{3}^{-}-\mathrm{N}$ 含量 $($ 表 4; 图4)。其中, 蔗糖酶活性与土壤 $\mathrm{pH}$ 、土壤全 $\mathrm{P} 、$ 微生物生物量 $\mathrm{P} 、$ 微生物生物量 $\mathrm{N}$ 以及土壤 $\mathrm{NO}_{3}^{-}-\mathrm{N}$ 含 量呈较强的正相关关系, 与微生物生物量 $\mathrm{C}: \mathrm{P}$ 、微生 物生物量 $\mathrm{C}: \mathrm{N}$ 、土壤 $\mathrm{N}: \mathrm{P}$ 、微生物生物量 $\mathrm{C}$ 含量、土 壤 $\mathrm{C}: \mathrm{P}$ 以及土壤 $\mathrm{NH}_{4}^{+}-\mathrm{N}$ 含量呈较强的负相关关系; 嫝酶和磷酸酶活性与以上因子的关系均与蔗糖酶活 性的相反。

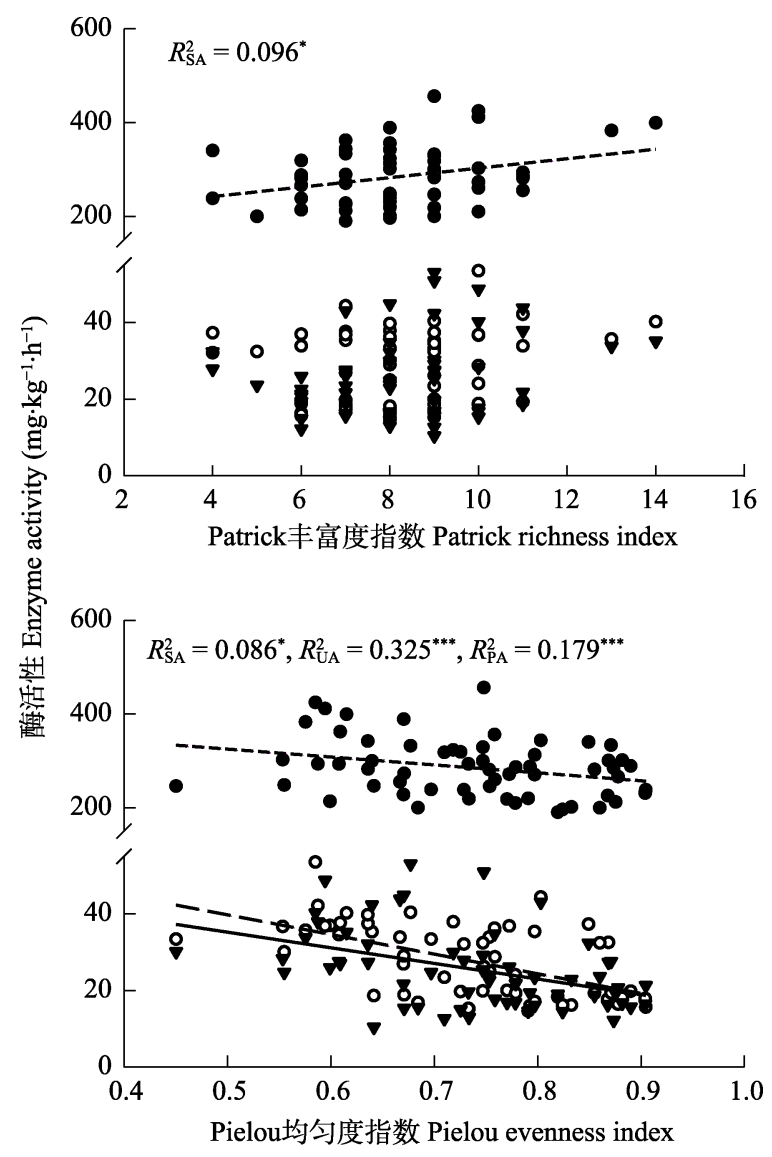

\section{3 讨论}

\section{1 土壤酶活性对降水量及 $\mathrm{N}$ 添加的响应}

本研究中, 减少降水量对蔗糖酶、脲酶和磷酸 酶活性的影响较小, 增加降水量不同程度地影响 3 种酶的活性。这可能是由于研究区长期处于低水平 的土壤水分环境下，植物和微生物对干旱具有高的 适应性(胡小文等，2004; 朱义族等，2019), 因而减
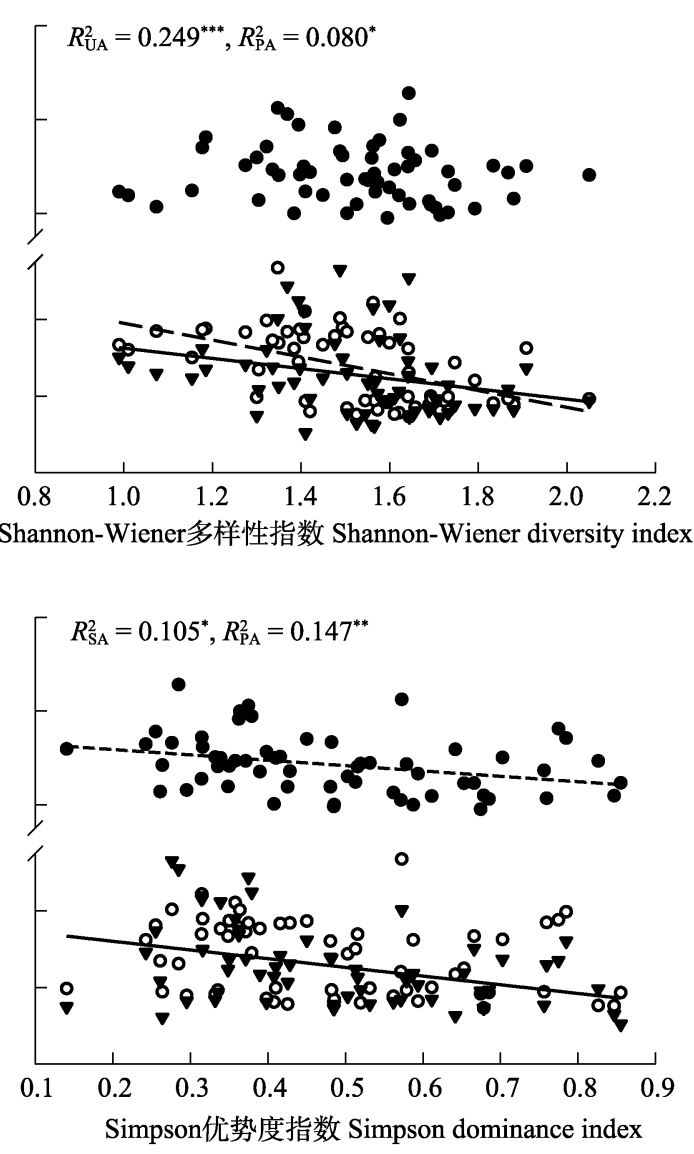

$\bullet-\cdots$ SA UA PA

图3 荒漠草原土壤酶活性与植物群落多样性的关系。SA、UA和PA分别代表蔗糖酶、䐂酶和磷酸酶活性。* ***和***分别 表示 $p<0.05 、 p<0.01$ 和 $p<0.001$ 。

Fig. 3 Relationships between soil enzyme activities and plant community diversity in desert steppe. SA, UA, and PA represent sucrase, urease, and phosphatase activities, respectively. *, ** and *** indicate $p<0.05, p<0.01$ and $p<0.001$, respectively.

表4 罙余分析中各环境因子的条件效应

Table 4 Conditional effects of environmental factors in redundancy analysis

\begin{tabular}{|c|c|c|c|c|c|c|c|c|c|c|c|c|c|c|c|c|c|c|}
\hline $\begin{array}{l}\text { 指标 } \\
\text { Index }\end{array}$ & $\mathrm{pH}$ & $T P$ & $\mathrm{C}: \mathrm{P}_{\mathrm{m}}$ & $\mathrm{C}: \mathrm{N}_{\mathrm{m}}$ & $\mathrm{N}: \mathrm{P}_{\mathrm{s}}$ & $M B C$ & $M B P$ & $\mathrm{C}: \mathrm{P}_{\mathrm{s}}$ & $\mathrm{NH}_{4}^{+}-\mathrm{N}$ & $M B N$ & $\mathrm{NO}_{3}^{-}-\mathrm{N}$ & $\mathrm{N}: \mathrm{P}_{\mathrm{m}}$ & $S W C$ & SOC & $T N$ & $E C$ & $A P$ & $\mathrm{C}: \mathrm{N}_{\mathrm{s}}$ \\
\hline$F$ & 53.7 & 37.3 & 28.4 & 28.0 & 27.2 & 22.4 & 20.1 & 18.4 & 17.9 & 16.4 & 5.9 & 2.5 & 1.1 & 1.0 & 0.9 & 0.4 & 0.3 & 0.2 \\
\hline$p$ & 0.002 & 0.002 & 0.002 & 0.002 & 0.002 & 0.002 & 0.002 & 0.002 & 0.002 & 0.002 & 0.016 & 0.110 & 0.266 & 0.318 & 0.356 & 0.638 & 0.676 & 0.776 \\
\hline
\end{tabular}




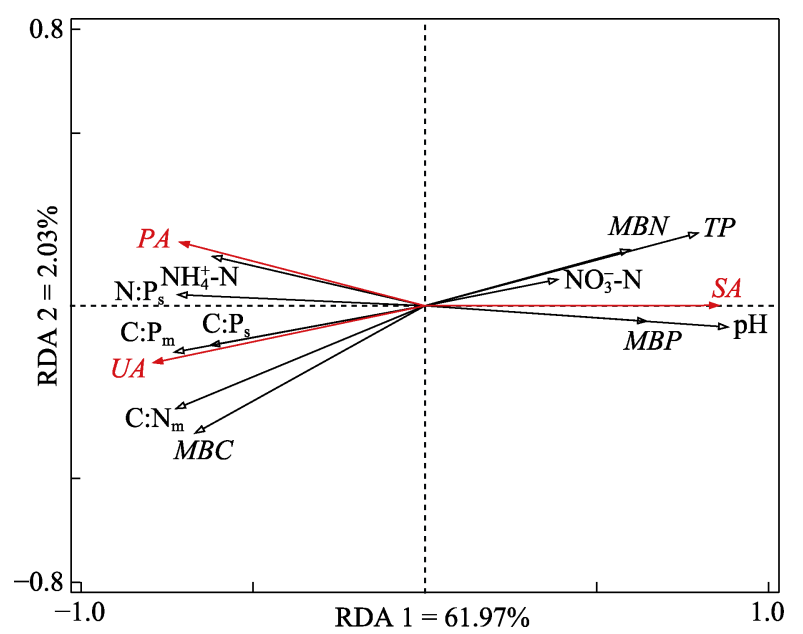

图4 土壤酶活性与微生物生态化学计量特征及其他环境因 子的圥余分析(RDA)。SA、UA和PA分别代表庶糖酶、脲酶 和磷酸酶活性。TP、C: $\mathrm{P}_{\mathrm{s}}$ 和 $\mathrm{N}: \mathrm{P}_{\mathrm{s}}$ 分别代表土壤全 $\mathrm{P}$ 含量、 $\mathrm{C}: \mathrm{P}$ 和 $\mathrm{N}: \mathrm{P} 。 M B C 、 M B N 、 M B P 、 \mathrm{C}: \mathrm{N}_{\mathrm{m}}$ 和 $\mathrm{C}: \mathrm{P}_{\mathrm{m}}$ 分别代表微生物生 物量 $\mathrm{C} 、 \mathrm{~N} 、 \mathrm{P}$ 含量, $\mathrm{C}: \mathrm{N}$ 和 $\mathrm{C}: \mathrm{P}$ 。 $\mathrm{NH}_{4}^{+}-\mathrm{N} 、 \mathrm{NO}_{3}^{-}-\mathrm{N}$ 分别代表土 壤 $\mathrm{NH}_{4}^{+}-\mathrm{N} 、 \mathrm{NO}_{3}^{-}-\mathrm{N}$ 含量。

Fig. 4 Redundancy analysis (RDA) of soil enzyme activities and microbial ecological stoichiometry and other environmental factors. SA, UA, and $P A$ represent sucrase, urease, and phosphatase activities, respectively. $T P, C: \mathrm{P}_{\mathrm{s}}$ and $\mathrm{N}: \mathrm{P}_{\mathrm{s}}$ represent soil total phosphorus content, $\mathrm{C}: \mathrm{P}$ and $\mathrm{N}: \mathrm{P}$, respectively. $M B C, M B N$, $M B P, C: \mathrm{N}_{\mathrm{m}}$ and $\mathrm{C}: \mathrm{P}_{\mathrm{m}}$ represent microbial biomass carbon, nitrogen, phosphorus content, $\mathrm{C}: \mathrm{N}$ and $\mathrm{C}: \mathrm{P}$, respectively. $\mathrm{NH}_{4}^{+}-\mathrm{N}$, $\mathrm{NO}_{3}^{-}-\mathrm{N}$ represent soil ammonium nitrogen, nitrate nitrogen content, respectively.

少降水量对其生长繁殖以及酶的分泌影响较小。相 比之下, 在缺水环境下, 增加降水量提高了土壤含 水量(附录III), 从而加速调落物淋溶、促进表层调落 物和腐殖质中可溶性物质进入土壤(豆鹏鹏等, 2018), 使微生物可利用底物增加, 微生物活性相应 增强，进而刺激微生物向环境中释放酶(Schimel et al., 2007), 即微生物分泌的酶随之增加。此外, 本 研究发现增加降水量对土壤酶活性的影响与N添加 存在交互作用, 与其他研究结果(王杰等, 2014a)相 似。这表明水分有利于 $\mathrm{N}$ 肥效的释放, 二者的交互作 用促进了植物生长(白春利等, 2013)、调落物积累以 及微生物活动(王杰等, 2014b), 进而刺激土壤酶的 分泌、导致土壤酶活性增强(间钟清等, 2017b)。

\section{2 土壤酶活性与植物群落组成的关系}

本研究中, 降水量和 $\mathrm{N}$ 添加下艮酶和磷酸酶活 性与草木樨状黄耆(豆科植物)生物量呈负线性关系, 而蔗糖酶、脲酶和磷酸酶活性均与䊁隐子草(禾本科 植物)生物量呈正线性关系, 与针对高寒草甸的研 究结果(王长庭等, 2010)存在差异。首先, 土壤酶活 性与植物生物量之间的关系因植物种不同而异。这
是由于不同植物根系的发达程度以及分泌物存在差 异, 进而影响土壤酶活性(王小平等, 2018)。豆科植 物与根瘤菌的共生作用可使其在相对干旱的条件下 快速生长(张仁懿等, 2014)。这不仅消耗了土壤养分, 而且抑制了微生物活性以及酶活性。相比之下，降 水量增加和 $\mathrm{N}$ 添加显著地刺激了禾本科植物的生长 (附录I; 朱湾湾等, 2019), 其自身的营养物质归还 土壤后可为土壤酶的合成提供丰富的底物(乔文静 等, 2018)。其次, 降水量增加及 $N$ 添加下植物生物量 增加(附录I; 朱湾湾等, 2019), 提高了调落物 C和养 分向土壤中的归还量(Zhong et al., 2017), 从而促进 了蔗糖酶、䐂酶和磷酸酶的产生。

研究表明, 土壤酶活性与植物群落多样性亦存 在不同程度的相关性(王长庭等, 2010; 乔文静等, 2018)。降水量和N添加及其交互作用改变了植物群 落多样性(附录II; 朱湾湾等, 2019), 因而可能会对 土壤酶活性产生重要影响。本研究中, 蔗糖酶活性 随着Patrick丰富度指数增加而增加, 即蔗糖酶活性 与植物物种数存在正线性关系。这可能是由于降水 量增加和 $\mathrm{N}$ 添加下, 随着植物物种数增多, 土壤酶 作用的底物多样性增加, 从而增强了蔗糖酶活性, 与对江河源区人工草地的研究结果(王启兰等, 2010) 一致; 嫝酶和磷酸酶活性均与 Shannon-Wiener多样 性指数以及Pielou均匀度指数存在负线性关系。这 可能是由于降水量和 $\mathrm{N}$ 添加下, 植物群落多样性和 均匀度的改变直接影响到土壤微环境(李长斌等, 2016), 并通过对植物根系和微生物活性的影响, 间 接影响到脲酶和磷酸酶活性。由于植物群落特征对 土壤酶活性的影响存在时间滞后效应(乔文静等, 2018), 因此还需通过长期的试验观测深入探讨土 壤酶活性与植物群落多样性之间的联系。

\section{3 土壤酶活性与微生物生态化学计量特征的关系}

除植物群落组成外, 土壤酶活性还受到土壤因 子的综合影响(王启兰等, 2010; 李静等, 2013)。本研 究中, 与其他因子相比, 微生物生态化学计量特征 对3种酶活性的影响较大。蔗糖酶活性与微生物生物 量 $\mathrm{C}$ 含量、 $\mathrm{C}: \mathrm{N}$ 和 $\mathrm{C}: \mathrm{P}$ 呈负相关关系。其可能原因在 于降水和 $\mathrm{N}$ 添加在一定程度上提高了土壤 $\mathrm{N}$ 和 $\mathrm{P}$ 的有 效性(涂利华等, 2009), 限制了 $\mathrm{C}$ 的有效性, 微生物 生物量 $\mathrm{C}$ 含量、 $\mathrm{C}: \mathrm{N}$ 和 $\mathrm{C}: \mathrm{P}$ 呈降低趋势(附录 $\mathrm{IV}$ ), 从而 刺激微生物分泌较多的 $\mathrm{C}$ 获取酶以促进有机 $\mathrm{C}$ 矿化 (Rappe-George et al., 2017)。腿酶活性与微生物生物 
量 C: $\mathrm{N}$ 呈正相关关系, 与微生物生物量 $\mathrm{N}$ 含量呈负 相关关系。这可能是由于持续增加的降水量加速了 土壤 $\mathrm{N}$ 淋溶, 导致土壤 $\mathrm{N}$ 含量降低(附录 $\mathrm{III}$ ), 即 $\mathrm{N}$ 受 限性增强，进而提高土壤脲酶活性以促进有机 $\mathrm{N}$ 矿 化(涂利华等, 2009; 刘星等, 2015)。此外, 磷酸酶活 性与微生物生物量 $\mathrm{C}: \mathrm{P}$ 呈正相关关系，与微生物生 物量P含量呈负相关关系。结合2019年磷酸酶的变 化特点(图1), 以上结果表明降水量变化和 $\mathrm{N}$ 添加下 微生物较多地受到土壤P有效性的限制。随着微生 物对 $\mathrm{P}$ 的需求量增加, 相关水解酶活性相应增强 (Steenbergh et al., 2011)。

此外, 对土壤酶活性影响显著的土壤因子还包 括 $\mathrm{pH}$ 、全P含量、 $\mathrm{N}: \mathrm{P} 、 \mathrm{C}: \mathrm{P} 、 \mathrm{NH}_{4}^{+}-\mathrm{N}$ 以及 $\mathrm{NO}_{3}^{-}-\mathrm{N}$ 含 量。土壤 $\mathrm{pH}$ 是影响土壤酶活性的重要因素(苏金等, 2020), 能够调控有机大分子物质的生物降解和矿 化过程(万忠梅和宋长春, 2009)。本研究中, 䐂酶和 磷酸酶活性均与土壤 $\mathrm{pH}$ 负相关, 意味着研究区土壤 较高的pH (附录III)抑制了二者活性, 与对森林土壤 的研究结果(吴际友等, 2010)一致。脲酶活性与土壤 $\mathrm{N}: \mathrm{P}$ 及及 $\mathrm{NH}_{4}^{+}-\mathrm{N}$ 含量正相关。这表明虽然 $\mathrm{N}$ 添加提高 了土壤 $\mathrm{N}$ 有效性, 但逐渐增加的降水量导致土壤 $\mathrm{N}$ 淋溶作用加强, 植物和微生物对 $\mathrm{N}$ 的竞争增强, 进 而导致服酶分泌量增多(刘星等, 2015)。另外, 磷酸 酶活性与土壤 $\mathrm{C}: \mathrm{P}$ 和 $\mathrm{N}: \mathrm{P}$ 正相关, 与全 $\mathrm{P}$ 含量负相关, 与其他研究结果(Allison et al., 2007)相似。这可能是 当土壤中 $\mathrm{P}$ 供给不足时, 植物会分泌磷酸酶以促进 土壤有机 $\mathrm{P}$ 的矿化, 生成可供植物吸收的无机态 $\mathrm{P}$ (附录 III), 导致土壤全 $\mathrm{P}$ 含量降低(Deng et al., 2017)。总之, 土壤pH和养分有效性通过调控养分固 定和矿化等过程, 以正、负效应的形式对土壤酶活 性进行调节和驱动。

\section{4 结论}

综上, 与减少降水量相比, 增加降水量对蔗糖 酶、脲酶和磷酸酶活性影响较大, 但其效应与 $\mathrm{N}$ 添加 以及年份存在交互作用; 与其他植物种相比, 草木 樨状黄耆和粘隐子草生物量与 3 种酶活性存在较强 的线性关系。Patrick丰富度指数与蔗糖酶活性存在 正的线性关系, Shannon-Wiener多样性指数、Pielou 均匀度指数以及 Simpson优势度指数均与 3 种酶活性 存在不同程度的负相关关系; 对土壤酶活性影响较 大的因子包括土壤 $\mathrm{pH}$ 、土壤全P含量、微生物生物
量 $\mathrm{C}: \mathrm{P}$ 、微生物生物量 $\mathrm{C}: \mathrm{N}$ 、土壤 $\mathrm{N}: \mathrm{P}$ 、微生物生物 量 $\mathrm{C}$ 和 $\mathrm{P}$ 含量。因此, 两年降水量及 $\mathrm{N}$ 添加下荒漠草 原土壤酶活性无明显的变化规律, 同时降水量和 $\mathrm{N}$ 添加通过改变植物群落组成、微生物生物量 $\mathrm{C}: \mathrm{N}: \mathrm{P}$ 生态化学计量特征以及土壤P有效性间接影响植被土壤系统中元素循环, 进而改变酶活性。

本研究为连续两年降水量变化和 $\mathrm{N}$ 添加下的试 验观测结果。由于短期的试验结果易受到降水和温 度等气候因子年际波动的影响, 因此有必要通过长 期的原位试验深入探讨土壤酶活性与植物、微生物 之间的联系。此外，鉴于土壤酶种类的多样化和功 能的复杂性以及土壤酶活性对于生态系统C、N、P 循环的重要指示意义, 今后还需结合鲜土中多种酶 活性的变化规律, 系统分析全球变化对酶活性的影 响机制。

\section{参考文献}

Allison VJ, Condron LM, Peltzer DA, Richardson SJ, Turner BL (2007). Changes in enzyme activities and soil microbial community composition along carbon and nutrient gradients at the Franz Josef chronosequence, New Zealand. Soil Biology \& Biochemistry, 39, 1770-1781.

Bai CL, Alata, Chen HJ, Shan YM, Eerdunhua, Wang MJ (2013). Effects of addition of nitrogen and water on plant community characteristics of Stipa breviflora desert steppe. Chinese Journal of Grassland, 35(2), 69-75. [白春 利, 阿拉塔, 陈海军, 单玉梅, 额尔敦花, 王明玖 (2013). 氮素和水分添加对短花针茅荒漠草原植物群落 特征的影响. 中国草地学报, 35(2), 69-75.]

Burns RG, DeForest JL, Marxsen J, Sinsabaugh RL, Stromberger ME, Wallenstein MD, Weintraub MN, Zoppini A (2013). Soil enzymes in a changing environment: current knowledge and future directions. Soil Biology \& Biochemistry, 58, 216-234.

Deng Q, Hui DF, Dennis S, Reddy KC (2017). Responses of terrestrial ecosystem phosphorus cycling to nitrogen addition: a meta-analysis. Global Ecology and Biogeography, 26, 713-728.

Dou PP, Wang F, Ma Y, Pang M, Mi XC, Ma KP, Lin DM (2018). Response of litter carbon, nitrogen and phosphorus to simulated leaching. Chinese Science Bulletin, 63, 3114-3123. [豆鹏鹏, 王芳, 马瑜, 庞梅, 米湘成, 马克 平, 林敦梅 (2018). 叶调落物碳、氮和磷元素对模拟淋 溶的响应. 科学通报, 63, 3114-3123.]

Duan L, Hao JM, Xie SD, Zhou ZP (2002). Estimating critical loads of sulfur and nitrogen for Chinese soils by steady state method. Environmental Science, 23(2), 7-12. [段雷, 郝吉明, 谢绍东, 周中平 (2002). 用稳态法确定中国土 
壤的硫沉降和氮沉降临界负荷. 环境科学, 23(2), 7-12.]

Gao JQ, Yang XG, Dong CY, Li KN (2015). Precipitation resource changed characteristics in arid and humid regions in Northern China with climate changes. Transactions of the Chinese Society of Agricultural Engineering, 31(12), 99-110. [高继卿, 杨晓光, 董朝阳, 李克南 (2015). 气 候变化背景下中国北方干湿区降水资源变化特征分析. 农业工程学报, 31(12), 99-110.]

Gu FX, Huang M, Zhang YD, Yan HM, Li J, Guo R, Zhong XL (2016). Modeling the temporal-spatial patterns of atmospheric nitrogen deposition in China during 1961-2010. Acta Ecologica Sinica, 36, 3591-3600. [顾峰雪, 黄玫, 张 远东, 问慧敏, 李洁, 郭瑞, 钟秀丽 (2016). 1961-2010 年中国区域氮沉降时空格局模拟研究. 生态学报, 36, 3591-3600.]

$\mathrm{Hu}$ XW, Wang YR, Wu YP (2004). Research progress on eco-physiological responses of desert grassland plants to drought conditions. Acta Prataculturae Sinica, 13(3), 9-15. [胡小文, 王彦荣, 武艳培 (2004). 荒漠草原植物 抗旱生理生态学研究进展. 草业学报, 13(3), 9-15.]

IPCC (Intergovernmental Panel on Climate Change) (2013). Summary for policymakers/climate change: the physical science basis//Contribution of Working Group I to the Fifth Assessment Report of the Intergovernmental Panel on Climate Change. Cambridge University Press, Cambridge, UK. 20-107.

Kanakidou M, Myriokefalitakis S, Daskalakis N, Fanourgakis G, Nenes A, Baker AR, Tsigaridis K, Mihalopoulos N (2016). Past, present and future atmospheric nitrogen deposition. Journal of the Atmospheric Sciences, 73, 2039-2047.

Li CB, Peng YF, Zhao DZ, Ning Y, Zhou GY (2016). Effects of precipitation change and nitrogen addition on community structure and plant diversity in an alpine steppe on the Qinghai-Tibetan Plateau. Research of Soil and Water Conservation, 23(6), 185-191. [李长斌, 彭云峰, 赵殿智, 宁神, 周国英 (2016). 降水变化和氮素添加对青藏高原 高寒草原群落结构和物种多样性的影响. 水土保持研 究, 23(6), 185-191.]

Li J, Yu XY, Tang M (2013). Effects of different plants on soil microbial biomass and enzyme activities in Zhifangou watershed of Loess Plateau. Acta Botanica BorealiOccidentalia Sinica, 33, 387-393. [李静, 蔚晓燕, 唐明 (2013). 黄土高原纸坊沟流域不同植物对土壤微生物生 物量和土壤酶活性的影响. 西北植物学报, 33, 387-393.]

Li YH, Zhu HQ, Fang LZ, Li FD (2020). Soil enzyme activity characteristics and impact factors under plant communities of the Ebinur Lake wetland. Acta Ecologica Sinica, 40, 549-559. [李艳红, 朱海强, 方丽章, 李发东 (2020). 艾 比湖湿地植物群落土壤酶活性特征及影响因素. 生态 学报, 40, 549-559.]

Liu HM, Zhou GF, Li J, Wang LL, Wang H, Yang DL (2018).
Effects of nitrogen deposition on soil enzyme activities of Stipa baicalensis steppe. Ecology and Environmental Sciences, 27, 1387-1394. [刘红梅, 周广帆, 李洁, 王丽丽, 王慧, 杨殿林 (2018). 氮沉降对贝加尔针茅草原土壤酶 活性的影响. 生态环境学报, 27, 1387-1394.]

Liu X, Wang JS, Zhao XH (2015). Effects of simulated nitrogen deposition on the soil enzyme activities in a Pinus tabulaeformis forest at the Taiyue Mountain. Acta Ecologica Sinica, 35, 4613-4624. [刘星, 汪金松, 赵秀海 (2015). 模拟氮沉降对太岳山油松林土壤酶活性的影响. 生态学报, 35, 4613-4624.]

Lü XT, Kong DL, Pan QM, Simmons ME, Han XG (2012). Nitrogen and water availability interact to affect leaf stoichiometry in a semi-arid grassland. Oecologia, 168, 301-310.

Ma WW, Yao T, Jin P, Wang GJ, Zhang YX (2014). Characteristics of microorganisms and enzyme activity under two plant communities in desert steppe. Journal of Desert Research，34，176-183. [马文文，姚拓，靳鹏，王国基，张 玉霞 (2014). 荒漠草原2种植物群落土壤微生物及土壤 酶特征. 中国沙漠, 34, 176-183.]

Qiao WJ, Dai YY, Zhang W, Fu SY, Yang GH, Han XH, Chen ZX, Gao DX, Feng YZ (2018). Relationship between the vegetation community and soil nutrient and enzyme activity during the restoration of abandoned land in the loess hilly region. Environmental Science, 39, 5687-5698. [乔文 静, 戴银月, 张伟, 付淑月, 杨改河, 韩新辉, 陈正兴, 高德新，冯永忠 (2018). 黄土丘陵区撂荒恢复过程中植 物群落组成与土壤养分及酶活性变化的关系. 环境科 学, 39, 5687-5698.]

Rappe-George MO, Choma M, Čapek P, Börjesson G, Kaštovská E, Šantrůčková H, Gärdenäs AI (2017). Indications that long-term nitrogen loading limits carbon resources for soil microbes. Soil Biology \& Biochemistry, 115, 310-321.

Schimel J, Balser TC, Wallenstein M (2007). Microbial stress-response physiology and its implications for ecosystem function. Ecology, 88, 1386-1394.

Steenbergh AK, Bodelier PLE, Hoogveld HL, Slomp CP, Laanbroek HJ (2011). Phosphatases relieve carbon limitation of microbial activity in Baltic Sea sediments along a redox-gradient. Limnology and Oceanography, 56, 2018-2026.

Su X, Lu M, Feng CC, Guo YL, Yue ZH (2020). Responses of seasonal dynamic of soil enzyme activity to soil salinity in Songnen saline-alkali grassland. Chinese Journal of Grassland, 42(1), 127-134. [苏釒金, 卢嫚, 冯程程, 郭迎 岗, 岳中辉 (2020). 松嫩草地土壤酶活性对土壤盐分季 节动态的响应. 中国草地学报, 42(1), 127-134.]

Tian DS, Wang H, Sun J, Niu SL (2016). Global evidence on nitrogen saturation of terrestrial ecosystem net primary productivity. Environmental Research Letters, 11, 024012. DOI: 10.1088/1748-9326/11/2/024012.

www.plant-ecology.com 
Tu LH, Hu TX, Zhang J, Li RH, Dai HZ, Luo SH, Xiang YB, Huang LH (2009). Soil enzyme activities in a Pleioblastus amurus plantation in Rainy Area of West China under simulated nitrogen deposition. Chinese Journal of Applied Ecology, 20, 2943-2948. [涂利华, 胡庭兴, 张健, 李仁 洪, 戴洪忠, 雒守华, 向元彬, 黄立华 (2009). 华西雨 屏区苦竹林土壤酶活性对模拟氮沉降的响应. 应用生 态学报, 20, 2943-2948.]

Wan ZM, Song CC (2009). Advance on response of soil enzyme activity to ecological environment. Chinese Journal of Soil Science, 40, 951-956. [万忠梅, 宋长春 (2009). 土壤酶活性对生态环境的响应研究进展. 土壤通报, 40 , 951-956.]

Wang CT, Long RJ, Wang GX, Liu W, Wang QL, Zhang L, Wu PF (2010). Relationship between plant communities, characters, soil physical and chemical properties, and soil microbiology in alpine meadows. Acta Prataculturae Sinica, 19(6), 25-34. [王长庭, 龙瑞军, 王根绪, 刘伟, 王启兰, 张莉, 吴鹏飞 (2010). 高寒草甸群落地表植被 特征与土壤理化性状、土壤微生物之间的相关性研究. 草业学报, 19(6), 25-34.]

Wang J, Li G, Xiu WM, Song XL, Zhao JN, Yang DL (2014a). Effects of nitrogen and water on soil enzyme activity and soil microbial biomass in stipa baicalensis steppe, Inner Mongolia of North China. Journal of Agricultural Resources and Environment, 31, 237-245. [王杰, 李刚, 修 伟明, 宋晓龙, 赵建宁, 杨殿林 (2014a). 氮素和水分对 贝加尔针茅草原土壤酶活性和微生物量碳氮的影响. 农业资源与环境学报, 31, 237-245.]

Wang J, Li G, Xiu WM, Zhao JN, Wang H, Yang DL (2014b). Responses of soil microbial functional diversity to nitrogen and water input in Stipa baicalensis steppe, Inner Mongolia, Northern China. Acta Prataculturae Sinica, 23, 343-350. [王杰, 李刚, 修伟明, 赵建宁, 王慧, 杨殿林 (2014b). 贝加尔针茅草原土壤微生物功能多样性对氮 素和水分添加的响应. 草业学报, 23, 343-350.]

Wang QL, Wang CT, Liu W, Cao GM, Long RJ (2010). Changes in plant communities and soil enzyme activities of artificial grasslands in headwater areas of the Yangtze and Yellow rivers. Chinese Journal of Applied and Environmental Biology, 16, 662-666. [王启兰, 王长庭, 刘伟, 曹广民, 龙瑞军 (2010). 江河源区人工草地植物群落和 土壤酶活性变化. 应用与环境生物学报, 16, 662-666.]

Wang XP, Xiao X, Tang TW, Li YX, Xiao J (2018). Seasonal changes of the input of root exudates and its driving characteristics of rhizosphere microbe in a Cercidiphyllum japonicum Sieb. plantation. Bulletin of Botanical Research, $38 ， 47-55$. [王小平, 肖肖, 唐天文, 黎云祥, 肖娟 (2018). 连香树人工林根系分泌物输入季节性变化及其 驱动的根际微生物特性研究. 植物研究, 38, 47-55.]

Wu JY, Ye DB, Wang XJ (2010). Soil enzyme activity and its correlation with soil physical and chemical properties in suburban forests in Changsha City. Journal of Northeast Forestry University, 38(3), 97-99. [吴际友, 叶道碧, 王旭 军 (2010). 长沙市城郊森林土壤酶活性及其与土壤理 化性质的相关性. 东北林业大学学报, 38(3), 97-99.]

Xu H, He MZ, Sun Y (2018). Response of soil enzyme activities to precipitation regulation in arid desert areas. Journal of Lanzhou University (Natural Sciences), 54, 790-797. [许华, 何明珠, 孙岩 (2018). 干旱荒漠区土壤酶活性 对降水调控的响应. 兰州大学学报(自然科学版), 54, 790-797.]

Xu ZW, Li MH, Zimmermann NE, Li SP, Li H, Ren HY, Sun H, Han XG, Jiang Y, Jiang L (2018). Plant functional diversity modulates global environmental change effects on grassland productivity. Journal of Ecology, 106, 1941-1951.

Yan ZQ, Qi YC, Li SJ, Dong YS, Peng Q, He YL, Li ZL (2017a). Soil microorganisms and enzyme activity of grassland ecosystem affected by changes in precipitation pattern and increase in nitrogen deposition-A review. Microbiology China, 44，1481-1490. [间钟清, 齐玉春, 李素俭, 董云社, 彭琴, 贺云龙, 李兆林 (2017a). 降水 和氮沉降增加对草地土壤微生物与酶活性的影响研究 进展. 微生物学通报, 44, 1481-1490.]

Yan ZQ, Qi YC, Peng Q, Dong YS, Guo SF, He YL, Wang LQ, Li ZL (2017b). Effects of increased precipitation and nitrogen deposition on soil enzyme activities. Acta Ecologica Sinica, 37, 3019-3027. [间钟清, 齐玉春, 彭 琴, 董云社, 郭树芳, 贺云龙, 王丽芹, 李兆林 (2017b). 降水和氮沉降增加对草地土壤酶活性的影响. 生态学 报, 37, 3019-3027.]

Yang R, Zhao DP (2018). Characteristics of seasonal variation of precipitation in northwest vulnerable ecotone under the background of climate warming in the past 54 years. Research of Soil and Water Conservation, 25(6), 85-93. [杨 蓉, 赵多平 (2018). 气候变暖背景下西北脆弱带近54年 降水季节变化特征. 水土保持研究, 25(6), 85-93.]

Yang WQ, Wang KY (2002). Advances on soil enzymology. Chinese Journal of Applied and Environmental Biology, 8, 564-570. [杨万勤, 王开运 (2002). 土壤酶研究动态与 展望. 应用与环境生物学报, 8, 564-570.]

Yu G, Jia Y, He N, Zhu J, Chen Z, Wang Q, Piao S, Liu X, He H, Guo X, Wen Z, Li P, Ding G, Goulding K (2019). Stabilization of atmospheric nitrogen deposition in China over the past decade. Nature Geoscience, 12, 424-429.

Yu HL, He NP, Wang QF, Zhu JX, Gao Y, Zhang YH, Jia YL, Yu GR (2017). Development of atmospheric acid deposition in China from the 1990s to the 2010s. Environmental Pollution, 231, 182-190.

Zhang JF, Xu YQ (2016). Responses of plant biomass and net primary production to nitrogen fertilization and increased precipitation in re-grassed croplands in Duolun County of Inner Mongolia, China. Chinese Journal of EcoAgriculture, 24, 192-200. [张金风, 徐雨晴 (2016). 水氮 
添加对内蒙古多伦县退耕还草地生物量、生产力及其分 配的影响. 中国生态农业学报, 24, 192-200.]

Zhang MM, Fan SH, Guan FY, Yan YJ, Yin ZX, Huang LY (2020). Study on soil microbial biomass and enzyme activities in mixed forest of bamboo and broad-leaved trees. Soils, 52, 97-105. [张美曼, 范少辉, 官凤英, 晏颖杰, 尹 子旭, 黄兰鹰 (2020). 竹阔混交林土壤微生物生物量及 酶活性特征研究. 土壤, 52, 97-105.]

Zhang RY, Xu DH, Chen LY, Wang G (2014). Plant N status in the alpine grassland of the Qinghai-Tibet Plateau: base on the N:P stoichiometry. Environmental Science, 35, 1131-1137. [张仁懿, 徐当会, 陈凌云, 王刚 (2014). 基 于 $\mathrm{N}: \mathrm{P}$ 化学计量特征的高寒草甸植物养分状况研究. 环 境科学, 35, 1131-1137.]

Zhong Y, Yan WM, Wang RW, Shangguan ZP (2017). Differential responses of litter decomposition to nutrient addition and soil water availability with long-term vegetation re- covery. Biology and Fertility of Soils, 53, 939-949.

Zhu WW, Wang P, Fan J, Niu YB, Yu HL, Huang JY (2019). Effects of precipitation and $\mathrm{N}$ addition on soil C:N:P ecological stoichiometry and plant community composition in a desert steppe of Ningxia, northwestern China. Acta Prataculturae Sinica, 28(9), 33-44. [朱湾湾, 王攀, 樊瑾, 牛 玉斌，余海龙，黄菊荣 (2019). 降水量及N添加对宁夏 荒漠草原土壤 $\mathrm{C}: \mathrm{N}: \mathrm{P}$ 生态化学计量特征和植被群落组成 的影响. 草业学报, 28(9), 33-44.]

Zhu YZ, Li YY, Han JG, Yao HY (2019). Effects of changes in water status on soil microbes and their response mechanism: a review. Chinese Journal of Applied Ecology, 30, 4323-4332. [朱义族, 李雅颖, 韩继刚, 姚槐应 (2019). 水分条件变化对土壤微生物的影响及其响应机制研究 进展. 应用生态学报, 30, 4323-4332.]

责任编委: 程晓莉 编辑: 赵 航

附录I 2019年降水量和氮添加对植物生物量的影响

Supplement I Effects of precipitation and nitrogen addition on plant biomass in 2019

https://www.plant-ecology.com/fileup/1005-264X/PDF/cjpe.2020.0264-S1.pdf

附录II 2019年降水量和氮添加对植物群落多样性的影响

Supplement II Effects of precipitation and nitrogen addition on plant community diversity in 2019

https://www.plant-ecology.com/fileup/1005-264X/PDF/cjpe.2020.0264-S2.pdf

附录III 2019年降水量和氮添加对土壤理化性质的影响

Supplement III Effects of precipitation and nitrogen addition on physical and chemical properties of soil in 2019 https://www.plant-ecology.com/fileup/1005-264X/PDF/cjpe.2020.0264-S3.pdf

附录IV 2019年降水量和氮添加对微生物生态化学计量特征的影响

Supplement IV Effects of precipitation and nitrogen addition on microbial ecological stoichiometry in 2019

https://www.plant-ecology.com/fileup/1005-264X/PDF/cjpe.2020.0264-S4.pdf 
朱湾湾, 王攀，许艺馨，李春环，余海龙，黄菊荣 (2021). 降水量变化与氮添加下荒漠草原土壤酶活性及其 影响因素研究. 植物生态学报, 45, 309-320. DOI: 10.17521/cjpe.2020.0264

Zhu WW, Wang P, Xu YX, Li CH, Yu HL, Huang JY (2021). Soil enzyme activities and their influencing factors in a desert steppe of northwestern China under changing precipitation regimes and nitrogen addition. Chinese Journal of Plant Ecology, 45, 309-320. DOI: 10.17521/cjpe.2020.0264

https://www.plant-ecology.com/CN/10.17521/cjpe.2020.0264

附录 I 2019 年降水量和氮添加对植物生物量的影响(平均值土标准误, $\boldsymbol{n}=3$ )

Supplement I Effects of precipitation and nitrogen addition on plant biomass in $2019(\operatorname{mean} \pm S E, n=3)$

\begin{tabular}{|c|c|c|c|c|c|c|c|}
\hline $\begin{array}{l}\text { 处理 } \\
\text { Treatment }\end{array}$ & $\begin{array}{c}\text { 群落生物量 } \\
\text { Community biomass }\end{array}$ & $\begin{array}{c}\text { 牛枝子 } \\
\text { Lespedeza potaninii }\end{array}$ & $\begin{array}{c}\text { 草木樨状黄者 } \\
\text { Astragalus } \\
\text { melilotoides }\end{array}$ & $\begin{array}{c}\text { 白草 } \\
\text { Pennisetum } \\
\text { flaccidum }\end{array}$ & $\begin{array}{c}\text { 针茅 } \\
\text { Stipa capillata }\end{array}$ & $\begin{array}{c}\text { 糙隐子草 } \\
\text { Cleistogenes } \\
\text { squarrosa }\end{array}$ & $\begin{array}{c}\text { 其他物种 } \\
\text { Other species }\end{array}$ \\
\hline W1N0 & $37.68 \pm 11.62^{b}$ & $21.91 \pm 0.37^{\mathrm{b}}$ & $1.49 \pm 0.36^{\mathrm{b}}$ & $4.59 \pm 4.59^{\mathrm{a}}$ & $4.59 \pm 2.88^{\mathrm{ab}}$ & $0.34 \pm 0.23^{\mathrm{c}}$ & $4.76 \pm 0.41^{\mathrm{c}}$ \\
\hline W2N0 & $58.01 \pm 9.04^{\mathrm{b}}$ & $35.69 \pm 9.10^{\mathrm{ab}}$ & $0.35 \pm 0.26^{\mathrm{b}}$ & $7.59 \pm 3.64^{\mathrm{a}}$ & $1.98 \pm 1.16^{\mathrm{b}}$ & $0.98 \pm 0.98^{\mathrm{b}}$ & $2.41 \pm 0.88^{\mathrm{c}}$ \\
\hline W3N0 & $109.46 \pm 16.37^{\mathrm{a}}$ & $69.11 \pm 21.31^{\mathrm{a}}$ & $11.27 \pm 2.54^{\mathrm{a}}$ & $6.41 \pm 6.41^{\mathrm{a}}$ & $5.75 \pm 1.86^{\mathrm{ab}}$ & $11.84 \pm 1.88^{\mathrm{ab}}$ & $5.08 \pm 0.51^{\mathrm{c}}$ \\
\hline W4N0 & $112.26 \pm 6.77^{\mathrm{a}}$ & $57.93 \pm 16.27^{\mathrm{ab}}$ & $11.13 \pm 2.76^{\mathrm{a}}$ & $9.44 \pm 7.10^{\mathrm{a}}$ & $8.80 \pm 4.12^{\mathrm{ab}}$ & $12.94 \pm 0.88^{\mathrm{ab}}$ & $12.02 \pm 0.04^{\mathrm{b}}$ \\
\hline W5N0 & $115.89 \pm 14.02^{\mathrm{a}}$ & $46.75 \pm 11.49^{\mathrm{ab}}$ & $11.00 \pm 2.58^{\mathrm{a}}$ & $12.46 \pm 8.02^{\mathrm{a}}$ & $11.84 \pm 1.67^{\mathrm{a}}$ & $14.05 \pm 1.43^{\mathrm{a}}$ & $19.79 \pm 2.73^{\mathrm{a}}$ \\
\hline W1N5 & $46.32 \pm 5.50^{\mathrm{C}}$ & $36.88 \pm 6.47^{\mathrm{b}}$ & $4.61 \pm 4.43^{\mathrm{a}}$ & $1.53 \pm 1.52^{\mathrm{b}}$ & $2.88 \pm 2.24^{\mathrm{a}}$ & $0.23 \pm 0.13^{\mathrm{a}}$ & $0.18 \pm 0.02^{\mathrm{b}^{*}}$ \\
\hline W2N5 & $64.68 \pm 11.63^{\mathrm{bc}}$ & $33.85 \pm 4.30^{\mathrm{b}}$ & $7.20 \pm 0.43^{\mathrm{a}^{*}}$ & $6.50 \pm 6.00^{\mathrm{ab}}$ & $8.57 \pm 4.86^{\mathrm{a}}$ & $5.72 \pm 3.83^{\mathrm{a}}$ & $2.86 \pm 2.22^{\mathrm{b}}$ \\
\hline W3N5 & $115.13 \pm 14.23^{\mathrm{ab}}$ & $73.78 \pm 8.20^{\mathrm{ab}}$ & $9.78 \pm 4.66^{\mathrm{a}}$ & $4.39 \pm 4.39^{\mathrm{ab}}$ & $7.45 \pm 5.38^{\mathrm{a}}$ & $3.79 \pm 2.46^{\mathrm{a}}$ & $12.62 \pm 1.39^{\mathrm{a}^{*}}$ \\
\hline W4N5 & $121.83 \pm 16.18^{\mathrm{a}}$ & $80.69 \pm 19.57^{\mathrm{ab}}$ & $7.75 \pm 0.69^{\mathrm{a}}$ & $8.74 \pm 4.10^{\mathrm{ab}}$ & $8.37 \pm 2.44^{\mathrm{a}}$ & $6.03 \pm 2.89^{\mathrm{a}}$ & $13.60 \pm 1.61^{\mathrm{a}}$ \\
\hline W5N5 & $141.09 \pm 30.77^{\mathrm{a}}$ & $87.60 \pm 35.44^{\mathrm{a}}$ & $8.76 \pm 2.10^{\mathrm{a}}$ & $13.08 \pm 2.24^{\mathrm{a}}$ & $9.30 \pm 6.39^{\mathrm{a}}$ & $8.23 \pm 4.93^{\mathrm{a}}$ & $14.09 \pm 1.53^{\mathrm{a}}$ \\
\hline
\end{tabular}

N0 和 N5 表示氮添加处理分别为 0 和 $5 \mathrm{~g} \cdot \mathrm{m}^{-2} \cdot \mathrm{a}^{-1}$ 。W1, 降水量减少 $50 \% ; \mathrm{W} 2$, 降水量减少 $30 \% ; \mathrm{W} 3$, 自然降水量; W4, 降水量增加 30\%; W5, 降水量增 加 $50 \%$ 。

N0 and N5 indicate the nitrogen addition treatment is 0 and $5 \mathrm{~g} \cdot \mathrm{m}^{-2} \cdot \mathrm{a}^{-1}$, respectively. W1, $50 \%$ reduction in precipitation; W2, 30\% reduction in precipitation; W3, natural precipitation; W4, 30\% increase in precipitation; W5, 50\% increase in precipitation. 
朱湾湾, 王攀, 许艺馨, 李春环, 余海龙, 黄菊荣 (2021). 降水量变化与氮添加下荒漠草原土壤酶活性及其 影响因素研究. 植物生态学报, 45, 309-320. DOI: 10.17521/cjpe.2020.0264

Zhu WW, Wang P, Xu YX, Li CH, Yu HL, Huang JY (2021). Soil enzyme activities and their influencing factors in a desert steppe of northwestern China under changing precipitation regimes and nitrogen addition. Chinese Journal of Plant Ecology, 45, 309-320. DOI: 10.17521/cjpe.2020.0264

https://www.plant-ecology.com/CN/10.17521/cjpe.2020.0264

附录 II 2019 年降水量和氮添加对植物群落多样性的影响(平均值土标准误, $n=3$ )

Supplemental II Effects of precipitation and nitrogen addition on plant community diversity in $2019(\operatorname{mean} \pm S E, n=3)$

\begin{tabular}{|c|c|c|c|c|}
\hline $\begin{array}{l}\text { 处理 } \\
\text { Treatment }\end{array}$ & $\begin{array}{l}\text { Patrick 丰富度指数 } \\
\text { Patrick richness index }\end{array}$ & $\begin{array}{l}\text { Shannon-Wiener 多样性指数 } \\
\text { Shannon-Wiener diversity index }\end{array}$ & $\begin{array}{c}\text { Pielou 均匀度指数 } \\
\text { Pielou evenness index }\end{array}$ & $\begin{array}{c}\text { Simpson 优势度指数 } \\
\text { Simpson dominance index }\end{array}$ \\
\hline W1N0 & $5.67 \pm 0.88^{\mathrm{b}}$ & $1.15 \pm 0.06^{\mathrm{b}}$ & $0.69 \pm 0.08^{\mathrm{a}}$ & $0.60 \pm 0.03^{\mathrm{b}}$ \\
\hline W2N0 & $8.00 \pm 0.58^{\mathrm{ab}}$ & $1.50 \pm 0.05^{\mathrm{a}}$ & $0.72 \pm 0.04^{\mathrm{a}}$ & $0.70 \pm 0.03^{\mathrm{a}}$ \\
\hline W3N0 & $9.33 \pm 0.33^{\mathrm{a}}$ & $1.42 \pm 0.11^{\mathrm{a}}$ & $0.64 \pm 0.06^{\mathrm{a}}$ & $0.72 \pm 0.05^{\mathrm{a}}$ \\
\hline W4N0 & $9.66 \pm 2.19^{\mathrm{a}}$ & $1.50 \pm 0.09^{\mathrm{a}}$ & $0.68 \pm 0.06^{\mathrm{a}}$ & $0.74 \pm 0.03^{\mathrm{a}}$ \\
\hline W5N0 & $9.33 \pm 0.33^{\mathrm{a}}$ & $1.50 \pm 0.08^{\mathrm{a}}$ & $0.67 \pm 0.04^{\mathrm{a}}$ & $0.74 \pm 0.03^{\mathrm{a}}$ \\
\hline W1N5 & $6.33 \pm 1.20^{\mathrm{C}}$ & $1.15 \pm 0.08^{\mathrm{a}}$ & $0.65 \pm 0.05^{\mathrm{b}}$ & $0.33 \pm 0.08^{b^{*}}$ \\
\hline W2N5 & $6.00 \pm 0.58^{\mathrm{c}}$ & $1.43 \pm 0.06^{\mathrm{a}}$ & $0.80 \pm 0.03^{\mathrm{a}}$ & $0.51 \pm 0.14^{\mathrm{a}}$ \\
\hline W3N5 & $9.33 \pm 0.88^{\mathrm{ab}}$ & $1.35 \pm 0.18^{\mathrm{a}}$ & $0.60 \pm 0.08^{\mathrm{b}}$ & $0.54 \pm 0.08^{\mathrm{a}}$ \\
\hline W4N5 & $11.33 \pm 0.88^{\mathrm{a}}$ & $1.41 \pm 0.04^{\mathrm{a}}$ & $0.58 \pm 0.00^{\mathrm{b}}$ & $0.58 \pm 0.11^{\mathrm{a}}$ \\
\hline W5N5 & $8.33 \pm 0.33^{\mathrm{bc}}$ & $1.43 \pm 0.03^{\mathrm{a}}$ & $0.68 \pm 0.02^{\mathrm{ab}}$ & $0.62 \pm 0.05^{\mathrm{a}}$ \\
\hline
\end{tabular}

N0 和 N5 表示氮添加处理分别为 0 和 $5 \mathrm{~g} \cdot \mathrm{m}^{-2} \cdot \mathrm{a}^{-1}$ 。W1, 降水量减少 $50 \%$; W2, 降水量减少 $30 \%$; W3, 自然降水量; W4, 降水量增加 $30 \%$; W5, 降水量增 加 $50 \%$ 。

N0 and N5 indicate the nitrogen addition treatment is 0 and $5 \mathrm{~g} \cdot \mathrm{m}^{-2} \cdot \mathrm{a}^{-1}$, respectively. $\mathrm{W} 1,50 \%$ reduction in precipitation; W2, $30 \%$ reduction in precipitation; W3, natural precipitation; W4, 30\% increase in precipitation; W5, 50\% increase in precipitation. 
朱湾湾, 王攀，许艺馨，李春环，余海龙，黄菊䒯 (2021). 降水量变化与氮添加下荒漠草原土壤酶活性及其 影响因素研究. 植物生态学报, 45, 309-320. DOI: 10.17521/cjpe.2020.0264

Zhu WW, Wang P, Xu YX, Li CH, Yu HL, Huang JY (2021). Soil enzyme activities and their influencing factors in a desert steppe of northwestern China under changing precipitation regimes and nitrogen addition. Chinese Journal of Plant Ecology, 45, 309-320. DOI: 10.17521/cjpe.2020.0264

https://www.plant-ecology.com/CN/10.17521/cjpe.2020.0264

附录 III 2019 年降水量和氮添加对土壤理化性质的影响(平均值士标准误, $n=3$ )

Supplemental III Effects of precipitation and nitrogen addition on physical and chemical properties of soil in 2019 (mean \pm $S E, n=3)$

\begin{tabular}{|c|c|c|c|c|c|c|c|c|c|}
\hline $\begin{array}{l}\text { 处理 } \\
\text { Treatment }\end{array}$ & SWC & $\mathrm{pH}$ & $E C$ & $\mathrm{NH}_{4}^{+}-\mathrm{N}$ & $\mathrm{NO}_{3}^{-}-\mathrm{N}$ & $A P$ & $S O C$ & $T N$ & $T P$ \\
\hline W1N0 & $5.96 \pm 0.09^{c}$ & $8.31 \pm 0.01^{\mathrm{a}}$ & $136.63 \pm 6.58^{b}$ & $3.80 \pm 0.11^{\mathrm{a}}$ & $4.62 \pm 0.36^{\mathrm{ab}}$ & $1.54 \pm 0.20^{\mathrm{a}}$ & $2.73 \pm 0.01^{\mathrm{c}}$ & $0.43 \pm 0.01^{\mathrm{a}}$ & $0.26 \pm 0.00^{\mathrm{ab}}$ \\
\hline W2N0 & $6.06 \pm 0.17^{\mathrm{c}}$ & $8.42 \pm 0.03^{\mathrm{a}}$ & $119.15 \pm 2.81^{\mathrm{b}}$ & $2.80 \pm 0.71^{\mathrm{a}}$ & $2.99 \pm 0.38^{\mathrm{b}}$ & $1.64 \pm 0.29^{\mathrm{a}}$ & $2.78 \pm 0.01^{\mathrm{c}}$ & $0.41 \pm 0.00^{\mathrm{b}}$ & $0.27 \pm 0.00^{\mathrm{a}}$ \\
\hline W3N0 & $7.10 \pm 0.28^{\mathrm{c}}$ & $8.36 \pm 0.04^{\mathrm{a}}$ & $160.03 \pm 42.69^{b}$ & $2.58 \pm 0.78^{\mathrm{a}}$ & $2.82 \pm 0.35^{\mathrm{b}}$ & $1.71 \pm 0.09^{\mathrm{a}}$ & $2.79 \pm 0.01^{\mathrm{c}}$ & $0.40 \pm 0.01^{\mathrm{b}}$ & $0.26 \pm 0.00^{\mathrm{bc}}$ \\
\hline W4N0 & $10.12 \pm 1.46^{\mathrm{b}}$ & $8.41 \pm 0.06^{\mathrm{a}}$ & $420.33 \pm 33.02^{\mathrm{a}}$ & $4.45 \pm 1.30^{\mathrm{a}}$ & $5.00 \pm 0.26^{\mathrm{a}}$ & $1.85 \pm 0.38^{\mathrm{a}}$ & $2.97 \pm 0.03^{b}$ & $0.40 \pm 0.00^{\mathrm{b}}$ & $0.25 \pm 0.00^{c}$ \\
\hline W5N0 & $13.10 \pm 1.08^{\mathrm{a}}$ & $8.39 \pm 0.06^{\mathrm{a}}$ & $456.33 \pm 21.18^{\mathrm{a}}$ & $3.50 \pm 1.97^{\mathrm{a}}$ & $4.92 \pm 0.57^{\mathrm{ab}}$ & $1.66 \pm 0.12^{\mathrm{a}}$ & $3.23 \pm 0.04^{\mathrm{a}}$ & $0.40 \pm 0.01^{\mathrm{b}}$ & $0.25 \pm 0.01^{\mathrm{c}}$ \\
\hline W1N5 & $5.63 \pm 0.38^{\mathrm{c}}$ & $8.14 \pm 0.04^{\mathrm{a}}$ & $201.40 \pm 19.06^{\mathrm{c}^{*}}$ & $6.61 \pm 2.35^{\mathrm{a}^{*}}$ & $20.21 \pm 1.41^{\mathrm{a}^{*}}$ & $1.79 \pm 0.57^{\mathrm{a}}$ & $2.92 \pm 0.01^{\mathrm{c}^{*}}$ & $0.47 \pm 0.01^{\mathrm{a}}$ & $0.28 \pm 0.01^{\mathrm{a}}$ \\
\hline W2N5 & $5.98 \pm 0.23^{\mathrm{c}}$ & $8.23 \pm 0.03^{\mathrm{a}}$ & $183.33 \pm 14.86^{\mathrm{c}^{*}}$ & $5.32 \pm 0.36^{\mathrm{a}^{*}}$ & $14.30 \pm 1.80^{\mathrm{a}^{*}}$ & $2.11 \pm 0.35^{\mathrm{a}}$ & $2.82 \pm 0.07^{\mathrm{c}}$ & $0.46 \pm 0.01^{\mathrm{a}^{*}}$ & $0.27 \pm 0.00^{\mathrm{ab}}$ \\
\hline W3N5 & $6.99 \pm 0.44^{\mathrm{c}}$ & $8.27 \pm 0.01^{\mathrm{a}}$ & $141.83 \pm 3.64^{c}$ & $3.33 \pm 0.35^{\mathrm{b}}$ & $10.81 \pm 0.97^{\mathrm{b}^{*}}$ & $2.16 \pm 0.35^{\mathrm{a}}$ & $3.13 \pm 0.02^{\mathrm{b}^{*}}$ & $0.41 \pm 0.01^{\mathrm{b}}$ & $0.25 \pm 0.02^{\mathrm{abc}}$ \\
\hline W4N5 & $10.00 \pm 0.98^{\mathrm{b}}$ & $8.34 \pm 0.04^{\mathrm{a}}$ & $363.67 \pm 48.27^{\mathrm{b}^{*}}$ & $2.94 \pm 0.60^{\mathrm{b}}$ & $13.20 \pm 2.01^{\mathrm{a}^{*}}$ & $2.22 \pm 0.18^{\mathrm{a}}$ & $3.79 \pm 0.09^{\mathrm{a}}$ & $0.40 \pm 0.01^{\mathrm{b}}$ & $0.24 \pm 0.01^{\mathrm{bc}}$ \\
\hline W5N5 & $12.45 \pm 1.02^{\mathrm{a}}$ & $8.21 \pm 0.03^{\mathrm{a}}$ & $531.67 \pm 39.14^{\mathrm{a}^{*}}$ & $4.16 \pm 1.16^{\mathrm{ab}}$ & $16.03 \pm 3.25^{\mathrm{a}^{*}}$ & $2.23 \pm 0.32^{\mathrm{a}}$ & $3.19 \pm 0.03^{\mathrm{b}^{*}}$ & $0.37 \pm 0.01^{\mathrm{b}}$ & $0.23 \pm 0.01^{\mathrm{c}}$ \\
\hline $\begin{array}{l}\text { 水量增加 } \\
A P \text {, availal }\end{array}$ & b。 & Ac & $\mathrm{H}_{4}^{+}-\mathrm{N}$ 含量; $\mathrm{NO}_{3}^{-}-$ & , $\mathrm{NO}_{3}{ }^{-}-\mathrm{N}$ 含量 & ; SOC, 土壤有朾 & 硶今昜· SUUC & 土壤含水量; & $N$, 土壤全氮 & 量; $T P$, 土壤 \\
\hline
\end{tabular}


朱湾湾, 王攀, 许艺馨, 李春环, 余海龙, 黄菊荣 (2021). 降水量变化与氮添加下荒漠草原土壤酶活性及其 影响因素研究. 植物生态学报, 45, 309-320. DOI: 10.17521/cjpe.2020.0264

Zhu WW, Wang P, Xu YX, Li CH, Yu HL, Huang JY (2021). Soil enzyme activities and their influencing factors in a desert steppe of northwestern China under changing precipitation regimes and nitrogen addition. Chinese Journal of Plant Ecology, 45, 309-320. DOI: 10.17521/cjpe.2020.0264

https://www.plant-ecology.com/CN/10.17521/cjpe.2020.0264

附录 IV 2019 年降水量和氮添加对微生物 C:N:P 的影响(平均值土标准误, $n=3$ )

Supplemental IV Effects of precipitation and nitrogen addition on microbial C:N:P ecological stoichiometry in 2019 (mean \pm $S E, n=3)$

\begin{tabular}{|c|c|c|c|c|c|c|}
\hline $\begin{array}{l}\text { 处理 } \\
\text { Treatment }\end{array}$ & $M B C$ & $M B N$ & $M B P$ & $M B C: M B N$ & $M B C: M B N$ & $M B N: M B P$ \\
\hline W1N0 & $68.51 \pm 11.37^{\mathrm{b}}$ & $7.40 \pm 0.54^{\mathrm{b}}$ & $3.16 \pm 0.81^{\mathrm{a}}$ & $9.33 \pm 1.72^{\mathrm{a}}$ & $23.44 \pm 5.30^{\mathrm{b}}$ & $2.55 \pm 0.41^{\mathrm{b}}$ \\
\hline W2N0 & $113.23 \pm 2.84^{\mathrm{ab}}$ & $12.09 \pm 7.34^{\mathrm{ab}}$ & $1.11 \pm 0.19^{\mathrm{b}}$ & $20.27 \pm 10.71^{\mathrm{a}}$ & $108.75 \pm 19.24^{\mathrm{a}}$ & $11.19 \pm 5.93^{\mathrm{ab}}$ \\
\hline W3N0 & $123.07 \pm 29.48^{\mathrm{a}}$ & $9.15 \pm 0.19^{\mathrm{a}}$ & $0.77 \pm 0.01^{\mathrm{b}}$ & $13.35 \pm 3.05^{\mathrm{a}}$ & $159.15 \pm 38.15^{\mathrm{a}}$ & $11.83 \pm 0.37^{\mathrm{a}}$ \\
\hline W4N0 & $110.48 \pm 4.20^{\mathrm{ab}}$ & $13.34 \pm 0.91^{\mathrm{ab}}$ & $1.34 \pm 0.09^{b}$ & $8.34 \pm 0.54^{\mathrm{a}}$ & $83.06 \pm 5.77^{\mathrm{ab}}$ & $10.13 \pm 1.39^{\mathrm{ab}}$ \\
\hline W5N0 & $105.23 \pm 14.81^{\mathrm{ab}}$ & $10.36 \pm 2.63^{\mathrm{ab}}$ & $1.15 \pm 0.22^{\mathrm{b}}$ & $11.99 \pm 3.76^{\mathrm{a}}$ & $105.38 \pm 35.74^{\mathrm{a}}$ & $8.97 \pm 0.96^{\mathrm{ab}}$ \\
\hline W1N5 & $77.79 \pm 17.94^{\mathrm{b}}$ & $7.26 \pm 0.62^{\mathrm{a}}$ & $3.07 \pm 0.43^{\mathrm{a}}$ & $10.99 \pm 2.79^{\mathrm{a}}$ & $25.58 \pm 4.99^{\mathrm{b}}$ & $2.54 \pm 0.61^{\mathrm{a}}$ \\
\hline W2N5 & $126.48 \pm 23.12^{\mathrm{ab}}$ & $14.13 \pm 10.12^{\mathrm{a}}$ & $0.68 \pm 0.32^{b}$ & $41.26 \pm 31.57^{\mathrm{a}}$ & $239.71 \pm 61.95^{\mathrm{a}}$ & $36.64 \pm 26.57^{\mathrm{a}}$ \\
\hline W3N5 & $144.32 \pm 27.51^{\mathrm{a}}$ & $10.72 \pm 1.55^{\mathrm{a}}$ & $0.70 \pm 0.07^{\mathrm{b}}$ & $14.92 \pm 5.04^{\mathrm{a}}$ & $201.92 \pm 18.46^{\mathrm{a}}$ & $16.09 \pm 3.87^{\mathrm{a}}$ \\
\hline W4N5 & $115.30 \pm 5.37^{\mathrm{ab}}$ & $16.53 \pm 7.36^{\mathrm{a}}$ & $1.35 \pm 0.26^{\mathrm{b}}$ & $10.51 \pm 4.20^{\mathrm{a}}$ & $93.29 \pm 21.95^{\mathrm{b}}$ & $13.61 \pm 5.94^{\mathrm{a}}$ \\
\hline W5N5 & $76.42 \pm 10.54^{\mathrm{b}}$ & $12.32 \pm 3.22^{\mathrm{a}}$ & $0.98 \pm 0.25^{\mathrm{b}}$ & $7.68 \pm 2.89^{\mathrm{a}}$ & $85.08 \pm 18.18^{b}$ & $14.51 \pm 5.99^{\mathrm{a}}$ \\
\hline
\end{tabular}

$M B C 、 M B N 、 M B P$ 分别代表微生物生物量碳、氮、磷含量。 N0 和 N5 表示氮添加处理分别为 0 和 $5 \mathrm{~g} \cdot \mathrm{m}^{-2} \cdot \mathrm{a}^{-1}$ 。 $\mathrm{W} 1$, 降水量减少 $50 \%$; $\mathrm{W} 2$, 降水量减 少 $30 \%$; W3, 自然降水量; W4, 降水量增加 $30 \%$; W5, 降水量增加 $50 \%$ 。

$M B C, M B N$ and $M B P$ represent microbial biomass carbon, nitrogen and phosphorus content. N0 and N5 indicate the nitrogen addition treatment is 0 and 5 g $\mathrm{m}^{-}$ ${ }^{2} \cdot \mathrm{a}^{-1}$, respectively. W1, 50\% reduction in precipitation; W2, 30\% reduction in precipitation; W3, natural precipitation; W4, 30\% increase in precipitation; W5, 50\% increase in precipitation. 